\title{
Energy absorption during compression and impact of dry elastic-plastic spherical granules
}

\author{
Sergiy Antonyuk • Stefan Heinrich • Jürgen Tomas • \\ Niels G. Deen • Maureen S. van Buijtenen • \\ J. A. M. Kuipers
}

Received: 15 July 2008 / Published online: 13 January 2010

(C) The Author(s) 2010. This article is published with open access at Springerlink.com

\begin{abstract}
The discrete modelling and understanding of the particle dynamics in fluidized bed apparatuses, mixers, mills and others are based on the knowledge about the physical properties of particles and their mechanical behaviour during slow, fast and repeated stressing. In this paper model parameters (modulus of elasticity, stiffness, yield pressure, restitution coefficient and strength) of spherical granules $\left(\gamma-\mathrm{Al}_{2} \mathrm{O}_{3}\right.$, zeolites $4 \mathrm{~A}$ and $13 \mathrm{X}$, sodium benzoate) with different mechanical behaviour have been measured by single particle compression and impact tests. Starting with the elastic compression behaviour of granules as described by Hertz theory, a new contact model was developed to describe the force-displacement behaviour of elastic-plastic granules. The aim of this work is to understand the energy absorption during compression (slow stressing velocity of $0.02 \mathrm{~mm} / \mathrm{s}$ ) and impact (the impact velocity of $0.5-4.5 \mathrm{~m} / \mathrm{s}$ ) of granules. For all examined granules the estimated energy absorption during the impact is found to be far lower than that during compression. Moreover, the measured restitution coefficient is independent of the impact velocity in the examined range and independent of the load intensity by compression (i.e. maximum compressive load). In the case of repeated loading with a constant load amplitude, the granules show cyclic
\end{abstract}

S. Antonyuk $(\varangle) \cdot S$. Heinrich

Institute of Solids Process Engineering and Particle Technology,

Hamburg University of Technology, Denickestr. 15,

21073 Hamburg, Germany

e-mail: antonyuk@tuhh.de

J. Tomas

Institute of Process Engineering, Otto-von-Guericke-University

of Magdeburg, Universitaetsplatz 2, 39106 Magdeburg, Germany

N. G. Deen · M. S. van Buijtenen · J. A. M. Kuipers

Institute for Mechanics Processes and Control Twente, University

of Twente, PO Box 217, 7500 AE Enschede, The Netherlands hardening with increasing restitution coefficient up to a certain saturation in the plastic deformation. A model was proposed to describe the increase of the contact stiffness with the number of cycles. When the load amplitude is subsequently increased, further plastic deformation takes place and the restitution coefficient strongly decreases.

Keywords Granules · Energy absorption - Elastic-plastic behaviour $\cdot$ Restitution coefficient $\cdot$ Contact model

$\begin{array}{ll}\text { List of symbols } \\ d_{1} & \text { Diameter of the granule }(\mathrm{m}) \\ d_{k, p l} & \text { Diameter of plastic deformed contact area }(\mathrm{m}) \\ E^{*} & \text { Average modulus of elasticity } \\ & \text { of contact partners }\left(\mathrm{N} / \mathrm{m}^{2}\right) \\ E & \text { Modulus of elasticity }\left(\mathrm{N} / \mathrm{m}^{2}\right) \\ F & \text { Normal force }(\mathrm{N}) \\ F_{B} & \text { Breakage force }(\mathrm{N}) \\ F_{c y c}, F_{U} & \text { Maximum force during a loading cycle }(\mathrm{N}) \\ k_{n} & \text { Contact stiffness in the normal direction }(\mathrm{N} / \mathrm{m}) \\ & \text { of contact partners }\left(\mathrm{N} / \mathrm{m}^{2}\right) \\ e_{e} & \text { Restitution coefficient } \\ e_{e q} & \text { Equivalent restitution coefficient } \\ k_{n}^{*} & \text { The median contact stiffness } \\ m_{1} & \text { in normal direction }(\mathrm{N} / \mathrm{m}) \\ p_{F} & \text { Mass of the granule }(\mathrm{kg}) \\ R^{*} & \text { Plastic micro-yield strength of granule } \\ R_{1} & \left.\text { contact (N/m }{ }^{2}\right) \\ r_{k} & \text { Median radius of contact partners }(\mathrm{m}) \\ s & \text { Radius of the granule (m) } \\ & \text { Radius of the contact area (m) } \\ & \text { Displacement (m) }\end{array}$




$\begin{array}{ll}\mathrm{t} & \text { Time }(\mathrm{s}) \\ \mathrm{v}_{1} & \text { Impact velocity }(\mathrm{m} / \mathrm{s}) \\ \mathrm{v}_{1, \mathrm{~F}} & \begin{array}{l}\text { Minimum impact velocity which corresponds } \\ \text { to the yield point }(\mathrm{m} / \mathrm{s})\end{array} \\ \mathrm{v}_{B} & \text { Stressing velocity during compression test }(\mathrm{m} / \mathrm{s}) \\ W & \text { Loading energy }(\mathrm{J}) \\ W_{k i n} & \text { Kinetic energy }(\mathrm{J})\end{array}$

\section{Greek letters}

$\kappa_{A} \quad$ Elastic-plastic contact area coefficient

$v \quad$ Poisson ratio

$\Theta \quad$ Impact angle (deg)

$\rho_{1} \quad$ Density of the granule $\left(\mathrm{kg} / \mathrm{m}^{3}\right)$

$\rho_{f} \quad$ Air density $\left(\mathrm{kg} / \mathrm{m}^{3}\right)$

$\sigma_{\max }$ Strength of dominantly plastic granules $\left(\mathrm{N} / \mathrm{m}^{2}\right)$

$\omega_{\mathrm{R}} \quad$ Angular velocity of the granule after rebound $(\mathrm{rad} / \mathrm{s})$

$\begin{array}{ll}\text { Subscripts } \\ B & \text { Breakage } \\ e l & \text { Elastic } \\ e l-p l & \text { Elastic-plastic } \\ F & \text { Yield point, flow } \\ L & \text { Loading } \\ \text { max } & \text { Maximum } \\ n & \text { Normal } \\ R & \text { Restitution, rebound } \\ p l & \text { Plastic } \\ t & \text { Tangential } \\ t o t & \text { Total } \\ U & \text { Unloading } \\ z & \text { Current number of the cycle } \\ l \text { and } g & \text { Granule } \\ 2 \text { and } w & \text { Wall }\end{array}$

\section{Introduction}

Many products, e.g. catalysts, adsorbents, fertilizers, tablets etc., are often produced as granules. Obvious advantages of the granules in comparison to powders are higher packing density, better flow behaviour as well as less dust formation. Due to granulation some technological problems, like long time consolidation or segregation of the bulk materials in bunkers and transport containers can be avoided. Moreover, desirable properties such as a regular shape, chemical composition, narrow particle size distribution, porosity, internal surface can be obtained.

During the processing sequence, transportation and handling the granules are exposed to a lot of mechanical stressing due to granule-granule and granule-apparatus wall impacts (Fig. 1). Stressing intensity and frequency can be set equivalent to the conditions occurring in processing apparatus like dryers, conveyors, granulators or mixers.
The mechanical interactions of the granular assembly during a process can be studied by numerical simulation with the discrete element method (DEM) or discrete particle method (DPM). In the last ten-fifteen years, these methods found many applications in the mechanics of bulk materials, i.e. flow behaviour and discharge of silos $[8,49,50]$, filling and packing [111], shearing [25,35,47,61, 103], heap formation $[13,36,65]$, bed configuration and loading conditions in fall mills $[63,69,105]$, compression behaviour $[68,78]$, mixing and transportation [12,27,44,52,54,107], fluidised bed processes $[31,40,41,58,66,90,102,104,110,112]$, heat exchange processes $[41,50]$.

In these simulations, the mechanical interactions between particles as well as between particle and apparatus walls are calculated. These include the force and stress distributions within the bulk material, velocities and trajectories of individual particles. From the simulation, important process parameters are determined, like e.g. the residence time of a material in the apparatus during filling and discharge of bunkers as well as mixing or drying. Based on the special contact models the complicated behaviour of the cohesive and wet bulk materials can be predicted $[25,103]$. These simulations provide physical knowledge about the micro-macro interactions of particles and macroscopic particle bed behaviour, which can be used to achieve understanding and solution of frequently occurring breakdowns in the process due to flow disturbances and unstable mass flows.

Through DEM, the individual granules can be modelled as a realistic mechanical system of primary particles which are bonded by adhesion forces [6]. Hence, the important influences of the microstructure concerning porosity, density, primary particle distribution, stiffness of the primary particles, their elasticity or plasticity as well as binder properties of the granule on deformation and breakage behaviour can be examined. Many interesting results of single granule simulations have been reported in the literature [6,26,78, 82,95]. A new stage of modelling should be the simulation of an assembly of granules subjected to different stressing conditions. Hassanpour et al. [29] describe the deformation and breakage of an agglomerate within a bed of particles, subjected to shearing. Grof et al. [24] performed the simulations of uniaxial compression tests of needle-shaped agglomerates within a random packed bed. However, no simulation of a bed with granules containing many primary particles in micrometer size range has been provided. This is because of the large computational effort that is needed to simulate a very high number of small particles. The time step of DEM calculations that ensures numerical stability is proportional to the mass of the smallest particle in the system [6]. Therefore in the DEM/DPM-models the granules are usually represented as homogeneous particles $[31,40,58$, $66,67,78,110]$ and the influence of their microstructure is neglected. 
Fig. 1 Typical stressing of particles during agglomeration in a rotated drum $(\mathbf{a})$, granulation in fluidized bed (b), transportation (c) and discharge (d)

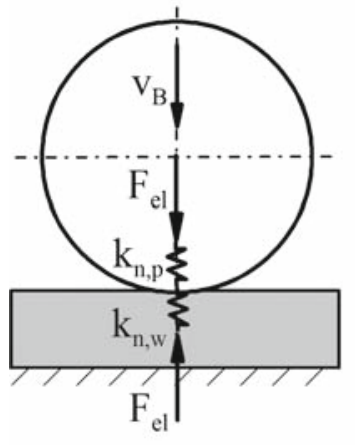

(a) impact

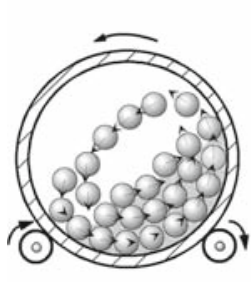

shearing impact compression

(a)

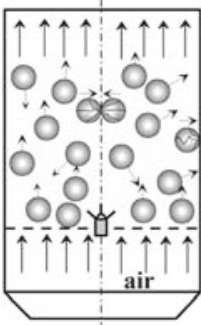

impact shearing (b)

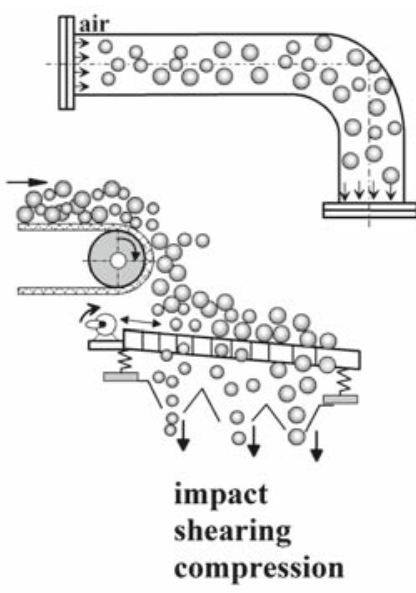

(c)

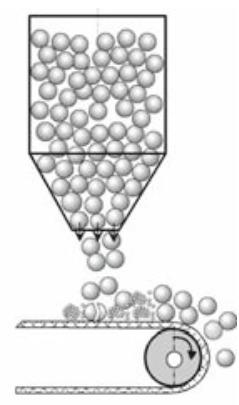

shearing compression impact

(d)
One objective is to describe the different force-displacement behaviour obtained by compression tests to determine the mechanical properties concerning the contact stiffness, modulus of elasticity, yield point as well as the restitution coefficient. The second objective is to compare the energy absorption of granules during slow compression and impact where the period of wall-granule interaction is very short. If the energy absorption in both stressing modes, at the same energy input, is nearly equal the data observed by simple compression test could be applied to modelling of impact stressing. The results will be used for the selection of an adequate contact model and for its following implementation in DPM for the modelling of particle collision and agglomeration in fluidized beds.

This paper is organized as follows: first, the contact models for elastic, elastic-plastic and plastic spherical particles by slow compression and impact are described. Based on these approaches the energy balance of granule loading is defined. In this work the dissipation energy in this balance is estimated using the restitution coefficient. Therefore, first the experimental methods and devices to measure this energetic parameter are described. Then, the different effects, which can influence the restitution coefficient, are discussed and a classification of the models to predict these effects is carried out. In the third chapter the materials and experimental setups used in this work are described. The experimental part consists on compression (slow loading) and free-fall tests (rapid stressing) which give the physical understanding of the energy absorption of the granules with different material behaviour. Due to compression tests the important effect of the repeated loading on the material parameters of granules is obtained. Concluding the experimental results the energy absorption of granules during compression and impact is compared. 


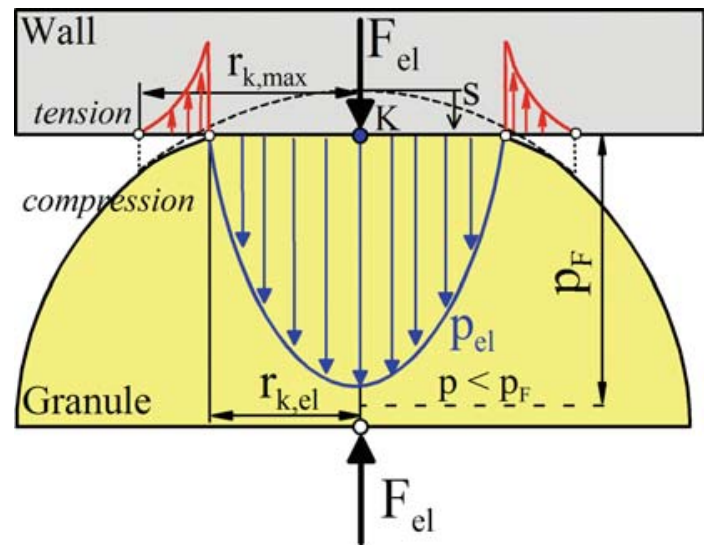

Fig. 3 Characteristic pressure distribution $p\left(r_{k}\right)$ in a wall-granule contact during elastic deformation

\section{Theoretical approaches}

\subsection{Characteristics of elastic contact deformation according to Hertzian theory}

During uniaxial loading of a comparatively soft spherical granule with a smooth stiff wall (flat surface), the contact area deforms as a circle (see Fig. 3). The contact radius, force and internal pressure distribution depend on the granule radius, stiffness and deformation behaviour (elastic, elastic-plastic or plastic) of the two contacting materials.

The pioneering work of Hertz [30] describes the elliptical pressure distribution $p_{e l}\left(r_{k}\right)$ in the circular contact area of a radius $r_{k, e l}$ (Fig. 3):

$$
\left(\frac{p_{e l}}{p_{\max }}\right)^{2}=1-\left(\frac{r_{k}}{r_{k, e l}}\right)^{2}, \quad r_{k} \leq r_{k, e l} .
$$

The tensile region at the perimeter of the contact pressure distribution is responsible for bending [89]. Therefore, the radius of the totally deformed area is larger than the contact radius: $r_{k, \max } \geq r_{k, e l}$ (Fig. 3).

Hertz also found that the maximum contact pressure in the centre of the contact area is given by:

$p_{\max }=\frac{3 F_{e l}}{2 \pi r_{k, e l}^{2}}$,

with a radius:

$r_{k, e l}=\left(\frac{3 R^{*} F_{e l}}{2 E^{*}}\right)^{1 / 3}$.

The effective modulus of elasticity $E^{*}$ of contact partner $\left(E_{2}>>E_{1}, E_{2} \rightarrow \infty\right)$ is given as:

$E^{*}=2\left(\frac{1-v_{1}^{2}}{E_{1}}+\frac{1-v_{2}^{2}}{E_{2}}\right)^{-1} \approx \frac{2}{1-v_{1}^{2}} E_{1}$, where $v$ is Poisson ratio. Note that we use index 1 for the granule and index 2 for the wall.

The median radius of contact partners $R^{*}$ is a characteristic radius of contact surface curvature:

$R^{*}=\left(\frac{1}{R_{1}}+\frac{1}{R_{2}}\right)^{-1} \approx R_{1}$.

The relation between elastic contact force and displacement in normal direction is non-linear as found by Hertz [30] for the point loading (Fig. 2a):

$F_{e l}=\frac{2}{3} E^{*} \sqrt{R^{*} s^{3}} \approx \frac{4}{3} \frac{E_{1}}{1-v_{1}^{2}} \sqrt{\frac{d_{1}}{2} s^{3}}$,

where $d_{1}$ is the granule diameter. $s$ is the full elastic displacement composed of the contact and of the whole sphere [30]:

$s=r_{k, e l}^{2} / R^{*}$.

Due to the parabolic curvature $F(s)$, the median contact stiffness in normal direction increases with increase in displacement $s$ and granule diameter $d_{1}$ [97]:

$k_{n, e l}^{*}=\frac{\mathrm{d} F_{e l}}{\mathrm{~d} s}=E^{*} \sqrt{R^{*} s} \approx \frac{\sqrt{2}}{1-v^{2}} E_{1} \sqrt{d_{1} s}$.

By impact stressing the median contact stiffness $k_{n, e l}^{*}$ equals the granule stiffness $k_{n, e l, g}$ since the granule is much softer than the wall $\left(k_{n, e l, w}\right)$ :

$k_{n, e l}^{*}=\left(\frac{1}{k_{n, e l, g}}+\frac{1}{k_{n, e l, w}}\right)^{-1} \approx k_{n, e l, g}$.

During compression with two plates (Fig. 2b) two contact areas are formed. In this case the force-displacement relationship for the compression can be given in analogy with Eq. (6) as:

$F_{e l, w-g-w}=\frac{1}{6} E^{*} \sqrt{d_{1} s^{3}} \approx \frac{1}{3} \frac{E_{1}}{\left(1-v_{1}^{2}\right)} \sqrt{d_{1} s^{3}}$.

Here, the displacement $s$ is the sum of the displacements of both contacts and of the whole granule ( $\mathrm{s}:=\mathrm{s} / 2)$.

The average elastic stiffness of this wall-granule-wall-systems results from sequence contacts, in Eq. (11). Hence, the mean contact stiffness $\left(k_{n, e l, w-g-w}^{*}\right)$, usually measured by a compression test, equals half the stiffness of granule $\left(k_{n, e l, g}\right)$ :

$$
\begin{aligned}
& k_{n, e l, w-g-w}^{*}=\frac{\mathrm{d} F_{e l, w-g-w}}{\mathrm{~d} s} \\
& =\frac{1}{4} E^{*} \sqrt{d_{1} s} \approx \frac{1}{2\left(1-v_{1}^{2}\right)} E_{1} \sqrt{d_{1} s} .
\end{aligned}
$$


Using Eq. (6) the work of elastic deformation during the impact can be written as:

$W_{e l}=\int_{0}^{s} F_{e l} \mathrm{~d} s=\frac{4}{15} E^{*} \sqrt{R^{*} s^{5}}=\frac{2}{5} F_{e l} s$.

The law of energy conservation during the elastic impact is given as:

$\frac{m^{*}}{2}\left(\frac{\mathrm{d} s}{\mathrm{~d} t}\right)^{2}+\frac{4}{15} E^{*} \sqrt{R^{*} s^{5}}=\frac{m^{*}}{2} v^{* 2}$,

where $m^{*}$ is effective mass of both contact partners and $\mathrm{v}^{*}$ is their relative impact velocity.

$m^{*}=\left(\frac{1}{m_{1}}+\frac{1}{m_{2}}\right)^{-1}$.

The maximum of the force $F_{e l, \text { max }}$ and overlap $\mathrm{s}_{e l, \text { max }}$, which are reached at zero relative velocity, as well as the time of impact $t_{e l}$, i.e. duration of contact, can be derived from the energy balance in Eq. (13) [56]:

$s_{e l, \max }=\left(\frac{225}{64} \frac{m^{* 2} v^{* 4}}{E^{* 2} R^{*}}\right)^{1 / 5}, \quad s_{e l, \max } \sim V^{* 4 / 5}$,

$F_{e l, \max }=\left(\frac{125 m^{* 3} E^{* 2} R^{*} v^{* 6}}{144}\right)^{1 / 5}, \quad F_{e l, \max } \sim V^{* 6 / 5}$,

$t_{e l}=3.78\left(\frac{m^{* 2}}{v^{*} R^{*} E^{* 2}}\right)^{1 / 5}, \quad t_{e l} \sim V^{*-1 / 5}$.

The Hertzian contact theory of the elastic spheres has certain restrictions regarding description of a dynamic collision [33]. The first condition of this theory can be formulated as follows: the contact pressure must increase slow enough to consider the quasi-static conditions. Secondly, the impact time must be longer than the propagation time of released elastic waves along the whole length of each body impacted, Eq. (18) [48]. In this case, their effect on the stress state is negligible.

$\frac{t_{e l}}{t_{w}}>>1$.

If expression (18) does not hold, the stress state is a result of advancing elastic or elastic-plastic waves [1,108]. The propagation time of the elastic wave into a contact partner $i$ along the normal impact can be given as:

$t_{w}=\frac{d_{i}}{\mathrm{v}_{w}}=d_{i}\left(\frac{\rho_{i}}{E_{i}}\right)^{1 / 2}$,

where $\mathrm{v}_{w}$ is wave propagation velocity.

Substituting the impact time according to Eq. (17) and the propagation time according to Eq. (19) into Eq. (18) gives the relative critical impact time: $t_{e l, c r i t}=\frac{t_{e l}}{t_{w}}=3.78\left(\frac{m^{* 2}}{v^{*} R^{*} E^{* 2}}\right)^{1 / 5}\left(\frac{E_{i}}{4 R_{i}^{2} \rho_{i}}\right)^{1 / 2}$,

where $\rho_{i}$ is the density of the contact partner $i$.

\subsection{Description of elastic-plastic contact deformation}

Because of the high pressure within the granule contact area (100-700 MPa, see experiments described below) the yield limit of the granule can be reached before the breakage. The plastic deformation starts when the maximum pressure in the centre of the contact reaches the micro-yield strength $\left(p=p_{\max }=p_{F}\right)$. Because of a confined stress field the micro-yield strength $p_{F}$ is higher than the macroscopic yield stress for tension $\sigma_{F, t}$ (Molerus 1975; Pisarenko 1986). The value $p_{F}$ was found by Davis [17] as $1.59 \times \sigma_{F, t}$. We assume for our granules that the pressure $p_{F}$ within the plastic contact area is a constant and that is deformation rate independent, i.e. the hardening effect is neglected.

When the granule diameter decreases, the contact pressure increases (see Eqs. 2 and 3). Thus at constant force the smaller granules behave softer than larger particles. The forcedisplacement curves measured in this work confirm the elastic-plastic behaviour of the granules beyond the yield point. In this case, neither the elastic nor the plastic contribution to the total deformation can be neglected.

The schematic representation of the applied mechanical model and the corresponding force-displacement curve in Fig. 4 explain the elastic-plastic behaviour. From the beginning of loading up to the yield point $\left(F<F_{F}\right)$ the forcedisplacement curve shows a nonlinear elastic deformation of sphere according to Hertz law. When the yield point is $\operatorname{reached}\left(F \geq F_{F}\right)$ plastic deformation follows, which is additionally affected by continuous elastic deformation ( $F_{e l, y}$ in Fig. 4a). The resulting normal contact force during elastic-plastic deformation is represented as superimposed spring and slider elements (Fig. 4a):

$F=F_{e l, y}+F_{p l}=F_{e l}$.

The plastic deformation is close to the contact centre of the circular contact area $\left(r_{k} \leq r_{k, p l}\right.$ in Fig. 5) and elastic deformation is generated at the limit of the contact ( $\operatorname{ring} r_{k}>r_{k, p l}$ ) where the pressure is smaller than the yield point.

Both areas increase with increasing deformation during the loading. An elastic-plastic contact area coefficient $\kappa_{A}$ represents the ratio of plastic contact deformation area $A_{p l}$ to total contact deformation area $A_{K}=A_{e l}+A_{p l}$, see Tomas [97]:

$\kappa_{A}=\frac{2}{3}+\frac{1}{3} \frac{A_{p l}}{A_{k}}$, 


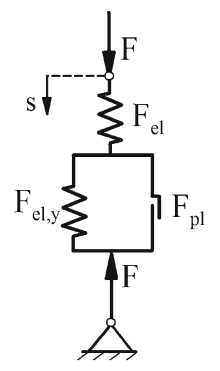

(a)

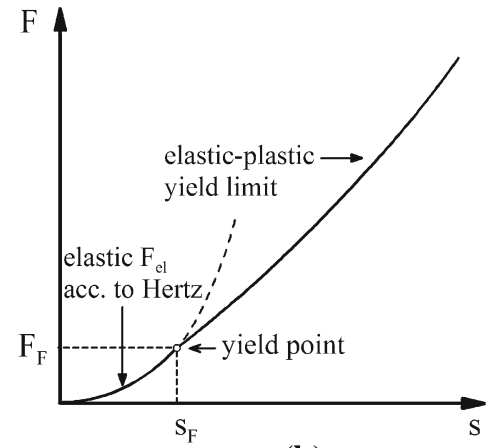

(b)
Fig. 4 Schematic of elastic-plastic contact model (a) for point loading in normal direction and corresponding force-displacement curve $\mathbf{b}$

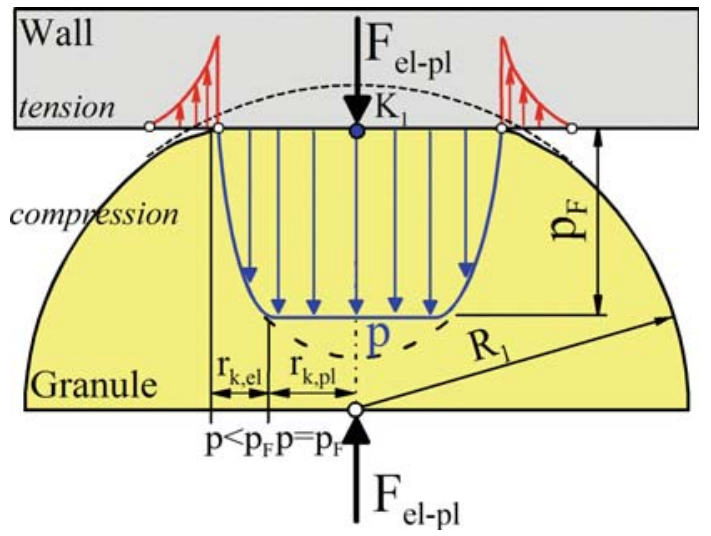

Fig. 5 Characteristic pressure distribution $p\left(r_{k}\right)$ in a wall-granule contact during elastic-plastic deformation

which after substituting the corresponding contact areas may be written as:

$\kappa_{A}=1-\frac{1}{3} \sqrt[3]{\frac{s_{F}}{S}}$,

where $s_{F}$ is the contact displacement at yield point. Eq. (23) is applicable to describe both compression and impact loading modes.

The ratio $A_{p l} / A_{k}$ is 0 for perfectly elastic $\left(A_{p l} \rightarrow 0\right)$ and 1 for perfectly plastic deformation $\left(A_{e l} \rightarrow 0\right)$. Thus the area coefficient $\kappa_{A}$ lies in the range between $2 / 3$ for ideally elastic behaviour to 1 for ideally plastic contact deformation.

The force-displacement relationship for elastic-plastic deformation $\left(s \geq s_{F}\right)$ during the point loading of the granule can be derived from the model of Tomas [97,103] by neglecting the adhesion in the contact ( $\kappa_{p}=0$ in [97]):

$F_{e l-p l}=\pi r_{k}^{2} p_{F} \kappa_{A}$.

Substituting Eqs. (7) and (23) into Eq. (24) we obtained the following expression:

$F_{e l-p l}=\pi R_{1} p_{F}\left(1-\frac{1}{3} \sqrt[3]{\frac{s_{F}}{s}}\right) s$.
The force-displacement curve at yield point $\left(s=s_{F}\right)$ changes from the elastic curve to elastic-plastic yield limit. Therefore, the Eqs. (25) and (6) should give equal values of the force at the yield point: $F_{e l}\left(s_{F}\right)=F_{e l-p l}\left(s_{F}\right)$. Hence, the microyield strength and the displacement at yield point can be derived $[94,96]$ :

$p_{F}=\frac{E^{*}}{\pi} \sqrt{\frac{s_{F}}{R_{1}}}$,

$s_{F}=\frac{\pi^{2} R_{1} p_{F}^{2}}{E^{* 2}}$.

The force at yield point can be found, substituting Eq. (27) into Eq. (6):

$F_{F}=\frac{2 \pi^{3} R_{1}^{2} p_{F}^{3}}{3 E^{* 2}}$.

From Eqs. (3) and (28) the contact radius at the beginning of plastic yielding $\left(s=s_{F}\right)$ may be written as [94]:

$r_{k, F}=\frac{\pi R_{1} p_{F}}{E^{*}}$.

The stiffness during the elastic-plastic displacement is proportional to the radius of the granule and micro-yield strength:

$k_{n, e l-p l}^{*}=\frac{\mathrm{d} F_{e l-p l}}{\mathrm{~d} s}=\pi R_{1} p_{F}\left(1-\frac{2}{9} \sqrt[3]{\frac{s_{F}}{s}}\right)$.

The elastic-plastic stiffness increases with increasing the displacement $s$. Due to change in the force-displacement curve from the elastic to the plastic range the stiffnesses of elastic and elastic-plastic displacement in the yield point are not equal. Their ratio at the beginning of yielding may be obtained from Eqs. (10), (25), (26) and (30), as follows:

$$
\begin{gathered}
\frac{k_{n, e l-p l}^{*}\left(s_{F}\right)}{k_{n, e l}^{*}\left(s_{F}\right)}=\frac{\left(1-\frac{2}{9}\right) \pi R_{1} p_{F}}{E^{*}\left(R_{1} s_{F}\right)^{\frac{1}{2}}} \\
=\frac{\left(1-\frac{2}{9}\right) E^{*}\left(R_{1} s_{F}\right)^{\frac{1}{2}}}{E^{*}\left(R_{1} s_{F}\right)^{\frac{1}{2}}}=\frac{7}{9} .
\end{gathered}
$$

In the case of uniaxial compression, the half of the total displacement must be considered in Eqs. (25) and (26) to calculate the micro-yield strength from the measured forcedisplacement curve:

$F_{e l-p l, w-g-w}=\pi R_{1} p_{F}\left(1-\frac{1}{3} \sqrt[3]{\frac{s_{F}}{s}}\right) \frac{s}{2}$.

\subsection{Dominantly plastic contact deformation of granules}

For dominantly plastic granules, the elastic range is much smaller in comparison with the plastic displacement. Thus, it can be assumed that the whole contact area deforms plastically and no surface deformation outside of the contact zone 


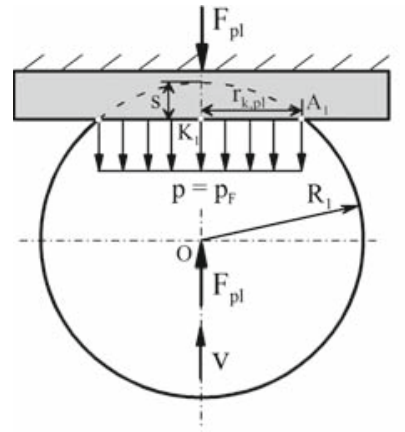

(a) impact

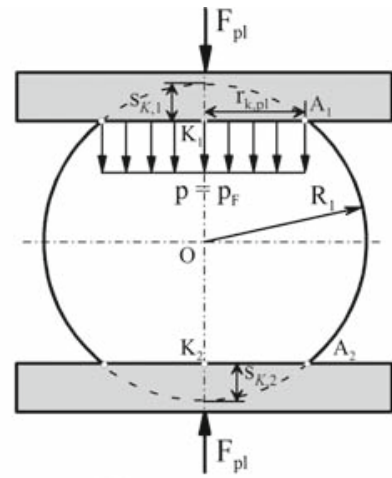

(b) compression
Fig. 6 Contact geometry by perfectly plastic deformation of the spherical granule

occurs. In case of point loading (Fig. 6a), the contact radius is given by:

$r_{k, p l}^{2}=R_{1}^{2}-\left(R_{1}-s\right)^{2}=2 R_{1} s-s^{2} \approx d_{1} s$.

Assuming that the plastic displacements at the two contacts are equal $\left(s_{K, 1}=s_{K, 2}, s=s_{K, 1}+s_{K, 2}\right.$, and $r_{k, p l, 1}=r_{k, p l, 2}$ in Fig. 6b), the contact radius by compression may be obtained as:

$r_{k, p l, w-g-w}^{2}=\mathrm{R}_{1} \mathrm{~s}$.

To model the plastic behaviour only a slider element is usually used [113]. The repulsive force against plastic displacement of the compressed granule is calculated as:

$F_{p l, w-g-w}=p_{F} A_{K}=\pi r_{k, p l}^{2} p_{F}=\pi R_{1} p_{F} s$

The contact stiffness is constant for a perfectly plastic yielding material:

$k_{n, p l, w-g-w}^{*}=\frac{\mathrm{d} F_{p l, w-g-w}}{\mathrm{~d} s}=\pi R_{1} p_{F}$.

\subsection{Energy balance of granule loading}

Based on the considerations for the deformation behaviour of a compressed granule given before, the energy balance of the loading can be written in the general form as:

$$
\begin{aligned}
\mathrm{W}_{\mathrm{L}}= & \mathrm{W}_{\mathrm{el}, \mathrm{el}}+\mathrm{W}_{\mathrm{el}-\mathrm{pl}}+\mathrm{W}_{\mathrm{diss}, \mathrm{add}}=\mathrm{W}_{\mathrm{el}, \mathrm{el}}+\mathrm{W}_{\mathrm{el}, \mathrm{el}-\mathrm{pl}} \\
& +\mathrm{W}_{\mathrm{pl}, \mathrm{el}-\mathrm{pl}}+\mathrm{W}_{\text {diss, add }},
\end{aligned}
$$

where $\mathrm{W}_{\mathrm{L}}$ is the full deformation work or energy absorption during the compression. $\mathrm{W}_{\mathrm{el}, \mathrm{el}}$ is the elastic strain energy done up to yield point. $\mathrm{W}_{\mathrm{el}, \mathrm{el}-\mathrm{pl}}$ and $\mathrm{W}_{\mathrm{pl}, \mathrm{el}-\mathrm{pl}}$ are elastic and plastic strain energy contribution, respectively, occurring during elastic-plastic deformation. $\mathrm{W}_{\text {diss,add }}$ is the energy loss due to friction which is mostly converted into heat.

The individual terms of Eq. (37) can be obtained by integrating the corresponding force-displacement relationships in Eqs. (10) and (32):

$$
\begin{aligned}
\mathrm{W}_{\mathrm{el}, \mathrm{el}} & =\int_{0}^{\mathrm{S}_{\mathrm{F}}} \mathrm{F}_{\mathrm{el}, \mathrm{w}-\mathrm{g}-\mathrm{w}} \mathrm{ds}=\frac{1}{15} \mathrm{E}^{*} \sqrt{\mathrm{d}_{1} \mathrm{~s}_{\mathrm{F}}^{5}}, \\
\mathrm{~W}_{\mathrm{el}-\mathrm{pl}} & =\int_{\mathrm{SF}_{\mathrm{F}}}^{\mathrm{s}} \mathrm{F}_{\mathrm{el}-\mathrm{pl}, \mathrm{w}-\mathrm{g}-\mathrm{w} \mathrm{ds}} \\
& =\frac{1}{8} \pi \mathrm{d}_{1} \mathrm{p}_{\mathrm{F}}\left[\mathrm{s}^{2}-\frac{3}{5}\left(1+\frac{2}{3}\left(\frac{\mathrm{s}}{\mathrm{s}_{\mathrm{F}}}\right)^{\frac{5}{3}}\right) \mathrm{s}_{\mathrm{F}}^{2}\right],
\end{aligned}
$$

where $s_{F}$ is the displacement in yield point and $s$ is the current displacement.

If the yield point is very low $\left(s_{F} \rightarrow 0\right)$ in comparison to the applied force, it can be assumed that plastic deformation starts from the beginning of loading and the full deformation work transforms in plastic deformation $\left(\mathrm{W}_{\mathrm{L}}=\mathrm{W}_{\mathrm{pl}}\right)$ irreversibly. The dissipative energy is obtained by integrating Eq. (35):

$$
\begin{aligned}
\mathrm{W}_{\mathrm{pl}} & =\int_{0}^{\mathrm{s}} \mathrm{F}_{\mathrm{pl}, \mathrm{w}-\mathrm{g}-\mathrm{w}} \mathrm{ds}=\frac{1}{2} \pi \mathrm{R}_{1} \mathrm{p}_{\mathrm{F}} \mathrm{s}^{2}=\frac{1}{2} \mathrm{~F}_{\mathrm{pl}, \mathrm{U}} \mathrm{s} \\
& =\frac{1}{2} \mathrm{k}_{\mathrm{n}, \mathrm{pl}, \mathrm{w}-\mathrm{g}-\mathrm{w}} \mathrm{s}^{2} .
\end{aligned}
$$

For some elastic-perfectly plastic granules the elastic strain energy is large in comparison with energy of the plastic deformation [78]. In this case, the yield point must be considered in the expression for the plastic force in Eq. (35) as $\mathrm{s}:=\mathrm{s}-\mathrm{s}_{\mathrm{F}}$ :

$\mathrm{F}_{\mathrm{pl}, \mathrm{w}-\mathrm{g}-\mathrm{w}}=\frac{1}{2} \pi \mathrm{d}_{1} \mathrm{p}_{\mathrm{F}}\left(\mathrm{s}-\mathrm{s}_{\mathrm{F}}\right)$.

The deformation work of elastic-perfectly plastic granule $\mathrm{W}_{\mathrm{el}, \mathrm{pl}}$ results from the sum of the elastic strain energy up to the yield point in Eq. (38) and the energy of the plastic deformation done by the force in Eq. (41). Insertion of the yield pressure (Eq. (26)) into Eq. (41), this deformation work results in:

$$
\begin{aligned}
\mathrm{W}_{\mathrm{el}, \mathrm{pl}} & =\int_{0}^{\mathrm{sF}} \mathrm{F}_{\mathrm{el}, \mathrm{w}-\mathrm{g}-\mathrm{w}} \mathrm{ds}+\int_{\mathrm{sF}}^{\mathrm{s}} \mathrm{F}_{\mathrm{pl}, \mathrm{w}-\mathrm{g}-\mathrm{w}} \mathrm{ds} \\
& =\frac{1}{5} \mathrm{E}^{*} \sqrt{\mathrm{d}_{1} \mathrm{~s}_{\mathrm{F}}^{5}}\left[1+\frac{15}{2}\left(\frac{\mathrm{s}}{\mathrm{s}_{\mathrm{F}}}-1\right)^{2}\right] .
\end{aligned}
$$

Additionally during granule stressing one has to consider friction between the primary particles sliding within their microscopic contacts, see Tomas [98,99]. The frictional microcontact behaviour contributes remarkably to the energy absorption of the stressed granule. 
2.5 Description of energy absorption using a restitution coefficient

\subsubsection{Measurement of the restitution coefficient of a granule}

The restitution coefficient is a very important parameter to describe the particle collisions in rapid particle or particlefluid flows [104]. This is an essential parameter which is needed to describe the energy absorption and damping force in numerical discrete modelling of particles [50,61,74,86]. The restitution coefficient is used in the field of granular matter and fluidized grains, more known as "granular gas" $[22,73]$, to model the inelastic behaviour of grains; see models of plane flows of circular disks [37], inelastic particles in a general flow field [62]. Moreover, several hydrodynamic models for granular gases are based on the hard sphere approaches, which include the restitution coefficient [9]. The complex dynamic evolution of granular gases, where the energy loss takes place due to inelastic deformation and friction by collisions, can be predicted using the models with normal and tangential restitution coefficients [114].

Figure 7 shows the contact force versus time and displacement in the impact between a comparatively soft spherical granule and a fixed stiff wall at different deformation behaviour. During the initial period of impact, i.e. compression, the contact partners are compressed and their kinetic energy is transformed into internal energy of deformation, friction and adhesion. The reaction force deforms the particle, which leads to the contact displacement or overlap. With increasing indentation the contact force increases and the relative velocity of contact partners decreases. If the deformation is rate-independent (elastic or plastic behaviour), the maximum indentation and maximum contact force occur at zero relative velocity [88].

The elastic contribution of the impact energy absorbed during the compression is released during the restitution phase of impact and leads to the elastic force that separates the contact partners. The absorption of the kinetic energy during the impact can be described by a restitution coefficient. The coefficient of restitution is a ratio of impulse during the restitution phase of impact $\left(t_{C} \leq t \leq t_{R}\right)$ to that during the compression phase $\left(0 \leq t \leq t_{C}\right)$, Eq. (43). Moreover, the impulse ratio in Eq. (43) gives the square root of the ratio of elastic strain energy $W_{k i n, R}$ released during the restitution to the impact energy, i.e. initial kinetic energy $W_{k i n}$.

$$
\begin{aligned}
e & =\frac{\int_{t_{c}}^{t_{R}} F \mathrm{~d} t}{\int_{0}^{t_{c}} F \mathrm{~d} t}=\sqrt{\frac{W_{k i n, R}}{W_{k i n}}}=\sqrt{1-\frac{W_{\text {diss }}}{W_{k i n}}} \\
& =\frac{\mathrm{v}_{1, R}}{\mathrm{v}_{1}} \approx \sqrt{\frac{h_{1, R}}{h_{1}}} .
\end{aligned}
$$

Both contributions of impact energy can be obtained by the force-displacement curve, Fig. 7b. Hence, the restitution coefficient is the square root of the ratio of the area below the curve during unloading (restitution) to that during loading (compression).

In case of a fully elastic impact the impact energy adsorbed during compression is fully restored during the rebound and so the relative velocity of contact partners before impact is equal to that after the impact, e $=1$ in Eq. (43). In the case of full absorption of initial kinetic energy due to plastic deformation, adhesion, friction in the contact as well as propagation of the stress waves, the impact bodies are not separated after the unloading (restitution), e = 0 in Eq. (43). The force-displacement curve of perfectly plastic contact partners does not show elastic restitution as illustrated in Fig. 7b. For elastic-plastic behaviour during the impact, the restitution coefficient is in the range of $0<\mathrm{e}<1$, see examples in $[5,15,16,20,23,28,34,55,59,60,71,76,83,85,88,91,92]$.

Two different types of impact, i.e. normal and oblique, are described by normal and tangential restitution coefficients:

$e_{n}=\mathrm{v}_{n, R} / \mathrm{v}_{n}$,

$e_{t}=\mathrm{v}_{t, R} / \mathrm{v}_{t}$,

where $\mathrm{v}_{\mathrm{n}}$ and $\mathrm{v}_{\mathrm{t}}$ are normal and tangential components of the velocity vector, respectively.

Different types of equipment were developed to measure the restitution coefficient, which can be divided into free-fall (a), particle-particle (b) and pendulum tests (c, d) illustrated in Fig. 8.

The most frequently used method to measure the restitution coefficient in both normal and tangential direction is the free-fall test (Fig. 8a), see examples in [23,60,71, 76, 85,92]. To describe the oblique impact the measurements are carried out at different impact angles, in the range from $0^{\circ}$ to $90^{\circ}$. The additional information about the impact behaviour can be obtained from rebound angle and the angular speed of rotation created during the rebound $[46,18]$.

Neglecting the fluid drag force acting upon particle during the free fall and rebound, the normal coefficient of restitution can also be determined as a ratio of heights after and before impact, $\mathrm{h}_{1, \mathrm{R}}$ and $\mathrm{h}_{1}$ in Eq. (43). These are measured by a simple free-fall test.

In the publications $[21,23,60]$ the restitution coefficient was measured without any initial spin of particles. The using of a vacuum nozzle prevents the initial rotation of the particle by releasing. On the other hand, to give a predefined rotation before collision the particle can be wrapped with a strip of paper, which will be unwrapped during the falling under gravity [18]. The angular velocity of the particle can be varied using strips with different unwrapped length. A disadvantage of this method is the possible slip of particle during the unwrapping. 
Fig. 7 Schematic representation of the contact force versus time (a) and displacement (b) at different deformation behaviour during the impact

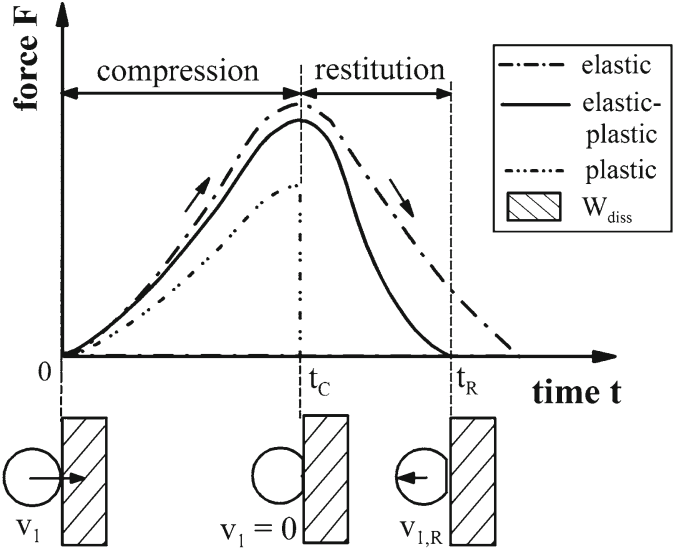

(a)

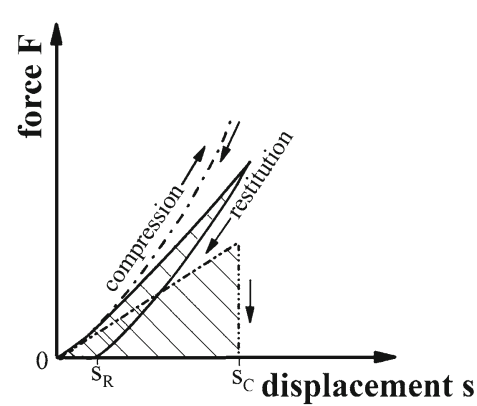

(b)
Fig. 8 Different testing methods for measurements of the restitution coefficient of particles

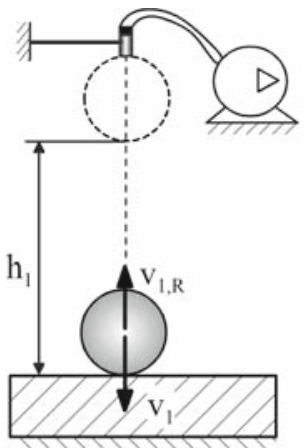

(a)

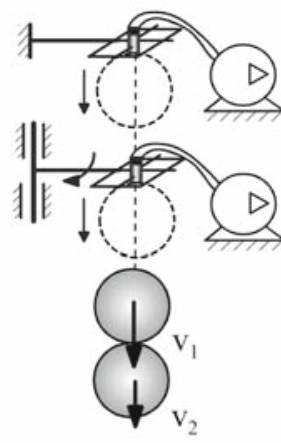

(b)

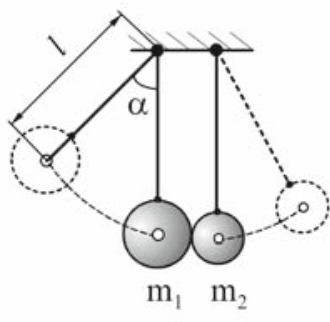

(c)

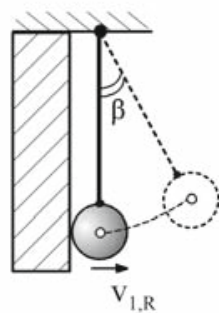

(d)

In many cases, the material of the target for experiments is chosen identical to walls of the apparatus or the tube of the investigated process. Using particle tracking velocimetry, Sommerfeld and Huber [85] obtained the influence of wall roughness and stiffness on the impact behaviour of glass and quartz particles in a particle-laden horizontal channel flow. Some authors have performed the impact of particles on the target with a layer, Fig. 8d. The knowledge of these impact characteristics is necessary to describe particle collisions in the presence of solid or liquid layers that occurs in some processes such as wet comminution, fluidized bed spray granulation, filtration etc. Kantak and Davis [42] have performed impact tests of steel and Teflon balls with wet or dry porous layers placed on a flat target from quartz. In the work of Huang et al. [32] the effects of milling conditions including impact velocity, ball size and powder thickness were studied by fall-tests. During these experiments a steel ball fell onto steel powder particles located in a shallow recess in the hardened steel plate.

For the particle-particle impact experiments, in contrast to the above category of devices, two particles collide without any rigid tool according to (Fig. 8b) $[15,20,55,59]$. This type of stressing occurs in fluidized bed granulation and comminution. The experimental device consists of two vacuum tweezers that are placed on top of each other to release the particles. The top particle is dropped first and reaches in a

definite time the falling height of the bottom particle. Before the impact the bottom vacuum noise of the second particle is quickly removed. A high-speed camera records the collision. To reach the central impact the release mechanisms of these devices should be accurate centred.

Pendulum-based experiments are also performed to measure the restitution coefficient in particle-wall [16,34], particle-particle [86,108] and particle-beam events [83]. Figure $8 \mathrm{c}$ schematically shows the pendulum experiments. Two particles are attached with thin wires to a horizontal overhead plate at a distance $l$. During the experiment the particles are simultaneously released and collide in normal direction. The relative impact velocity of a particle can be calculated from the distance between the overhead plane and impact point. The velocity of particles after the impact can be measured using high-speed video recording of impact [108] or some photodiodes [86]. The advantage of the pendulumbased experiments is the possibility to perform the impact at small impact velocities $(\mathrm{cm} / \mathrm{s})$, which is difficult to obtain in free-fall experiments because on the small falling height.

\subsubsection{Significant factors affecting the restitution coefficient}

The coefficient of restitution can depend on many parameters, like impact velocity, material behaviour of impacted 


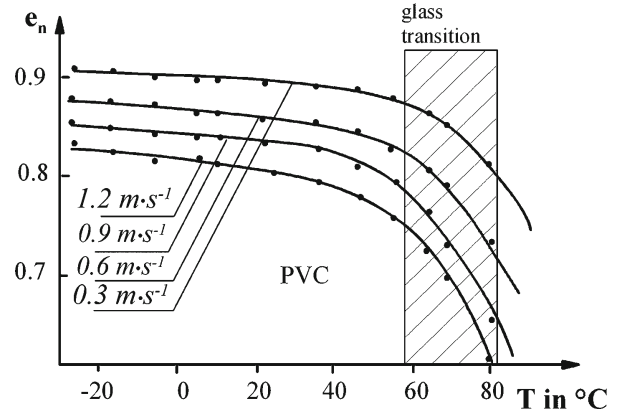

Fig. 9 Coefficient of restitution of spherical indentor made of tungsten carbide impacted on a PVC target as a function of the carbide temperature for four different impact velocities [75]

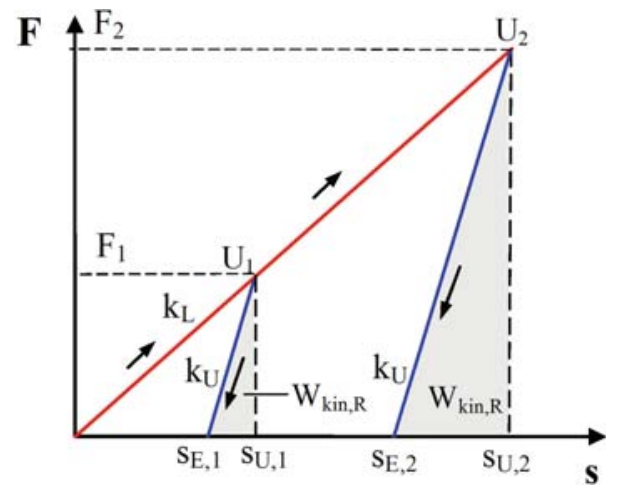

Fig. 10 The force-displacement curves according to the model of Walton and Braun

bodies, particle size, shape, roughness, moisture content, adhesion properties and process conditions, like temperature.

Increasing the material temperature can change the contact behaviour of particles from dominantly elastic to elasticplastic or viscoplastic. In this case the restitution coefficient is decreased. Figure 9 shows the results of impact tests between carbide and PVC at different temperatures. For a given impact velocity the decrease of the restitution coefficient with temperature increasing from $-20^{\circ} \mathrm{C}$ to $70^{\circ} \mathrm{C}$ (in the glassy state) is relatively small while a severe decrease can be observed at a temperature above $\sim 70^{\circ} \mathrm{C}$, as PVC begins to behave as a viscoplastic material [75].

As long as at least one of the contact partners does not start to yield, the restitution coefficient remains constant and only depends on material properties. If the contact force exceeds the yield point, the coefficient of restitution can decrease with increasing impact velocity, which was shown in many experimental studies [21,23,46,64,86] and described with the models [73,94].

This occurs because of increase in the energy absorption at higher impact velocities due to plastic deformation and heating of bodies contacted. In the case of constant restitution coefficient the ratio of the energy absorption during the impact to the kinetic impact energy in Eq. (46) remains constant for each impact velocity. This behaviour describes the well-know model of Walton and Braun [106] based on simple linear force-displacement relationships for loading $\left(F_{B}=k_{L} \times \mathrm{s}\right)$ and unloading $\left(F_{E}=k_{U} \times\left(s-s_{E}\right)\right)$, Fig. 10. Thus the ratio of energies from Eq. (43) can be reduced to the ratio of constant contact stiffness of load $k_{L}$ to contact stiffness $k_{U}$ of unload:

$$
\begin{aligned}
e & =\sqrt{\frac{W_{k i n, R}}{W_{k i n}}}=\sqrt{\frac{\int_{s_{E}}^{s_{U}} k_{U}\left(s-s_{E}\right) \mathrm{d} s}{\int_{0}^{s_{U}} k_{L} s \mathrm{~d} s}}=\sqrt{\frac{k_{U}\left(s_{U}-s_{E}\right)^{2}}{k_{L} s_{U}^{2}}} \\
& =\sqrt{\frac{k_{L}}{k_{U}}}
\end{aligned}
$$

The expression of Walton and Braun [106] is only one example of an approximation of particle impact behaviour that was presented here in detail since we used this model in the following description of restitution coefficient of the examined granules. However, many different models were developed to describe the restitution coefficient of viscoelastic (Schafer et al. [79], Stronge [88], Stoianovici and Harmuzlu [87]), viscoelastic-adhesive (Thornton and Ning), viscoelastic (Brilliantov [11]), elastic-perfectly plastic (Thornton [93], $\mathrm{Wu}$ et al. [109]), elastic-perfectly plastic adhesive (Thornton and Ning [94]), elastic-perfectly plastic with hardening (Mangwandi et al. [64]), elastic-plastic (Johnson [38]), elastic-viscoplastic (Adams et al. [3]), plastic and viscoplastic (Walton and Braun [106]), elastic-adhesive (Thornton and Ning [94]) contacts. A review of these models is given in Table 1.

\section{Methods and model granules}

\subsection{Examined granules}

Four different industrial spherical granules $-\gamma-\mathrm{Al}_{2} \mathrm{O}_{3}$, synthetic zeolite $13 \mathrm{X}$, synthetic zeolite $4 \mathrm{~A}$ and sodium benzoate $\left(\mathrm{C}_{6} \mathrm{H}_{5} \mathrm{CO}_{2} \mathrm{Na}\right)$ were used as test materials (Fig. 11).

Previously we have tested many other granules to find some model materials and selected these four granules for varying the deformation behaviour from elastic-plastic $\left(\gamma-\mathrm{Al}_{2} \mathrm{O}_{3}\right.$, zeolites) to plastic (sodium benzoate). An advantage of these particles is their comparable sizes. Because of a nearly ideally spherical shape (sphericity in the range of 0.91$0.95)$ it is possible to apply the contact theory of spheres for description of deformation and breakage behaviour of these granules.

A summary of the material properties of these granules is given in Table 2. The methods used to measure the properties were described in a previous publication [6]. We used two fractions of sodium benzoate in order to determine the influence of the particle size on the stiffness and restitution coef- 


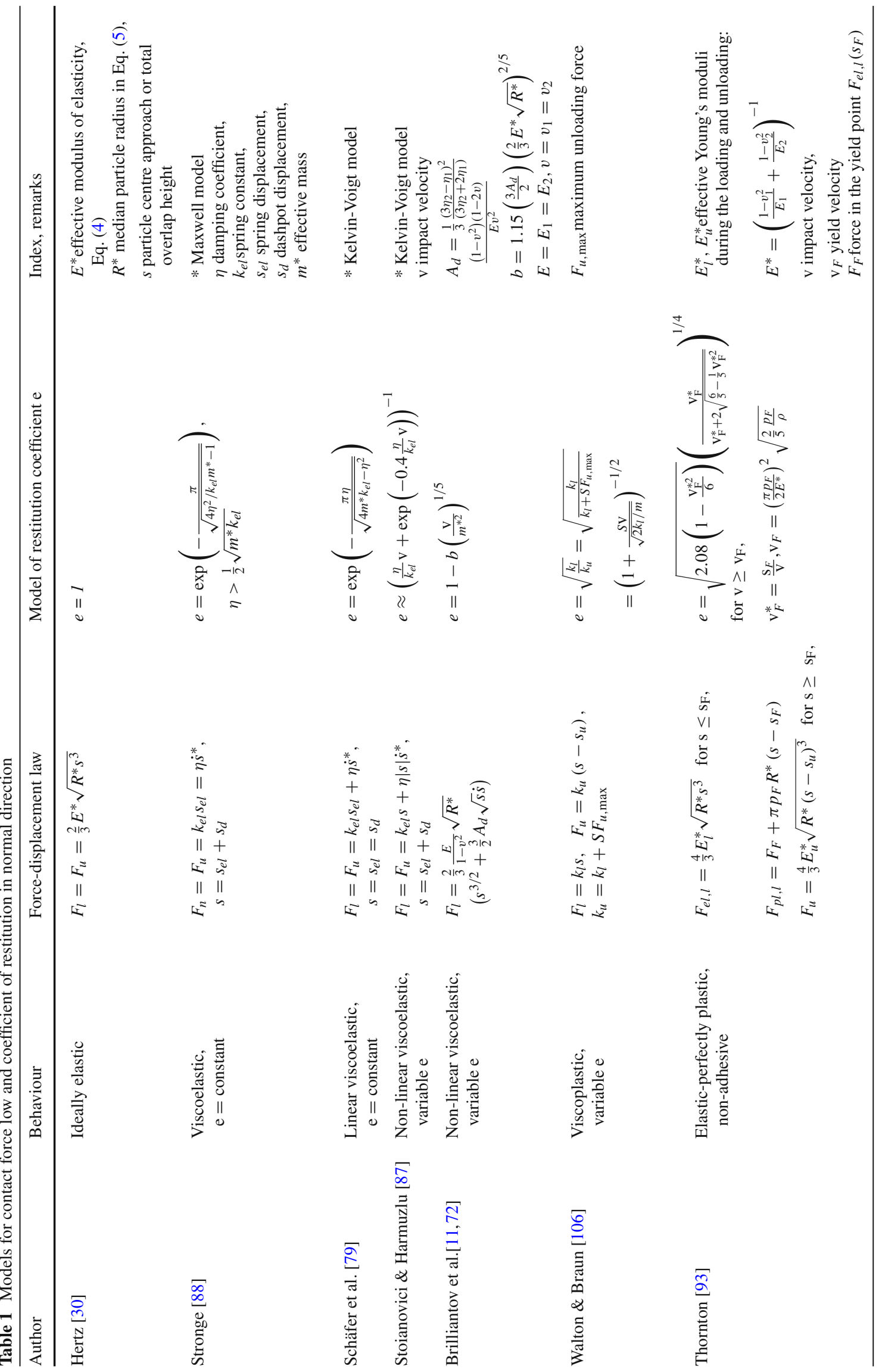




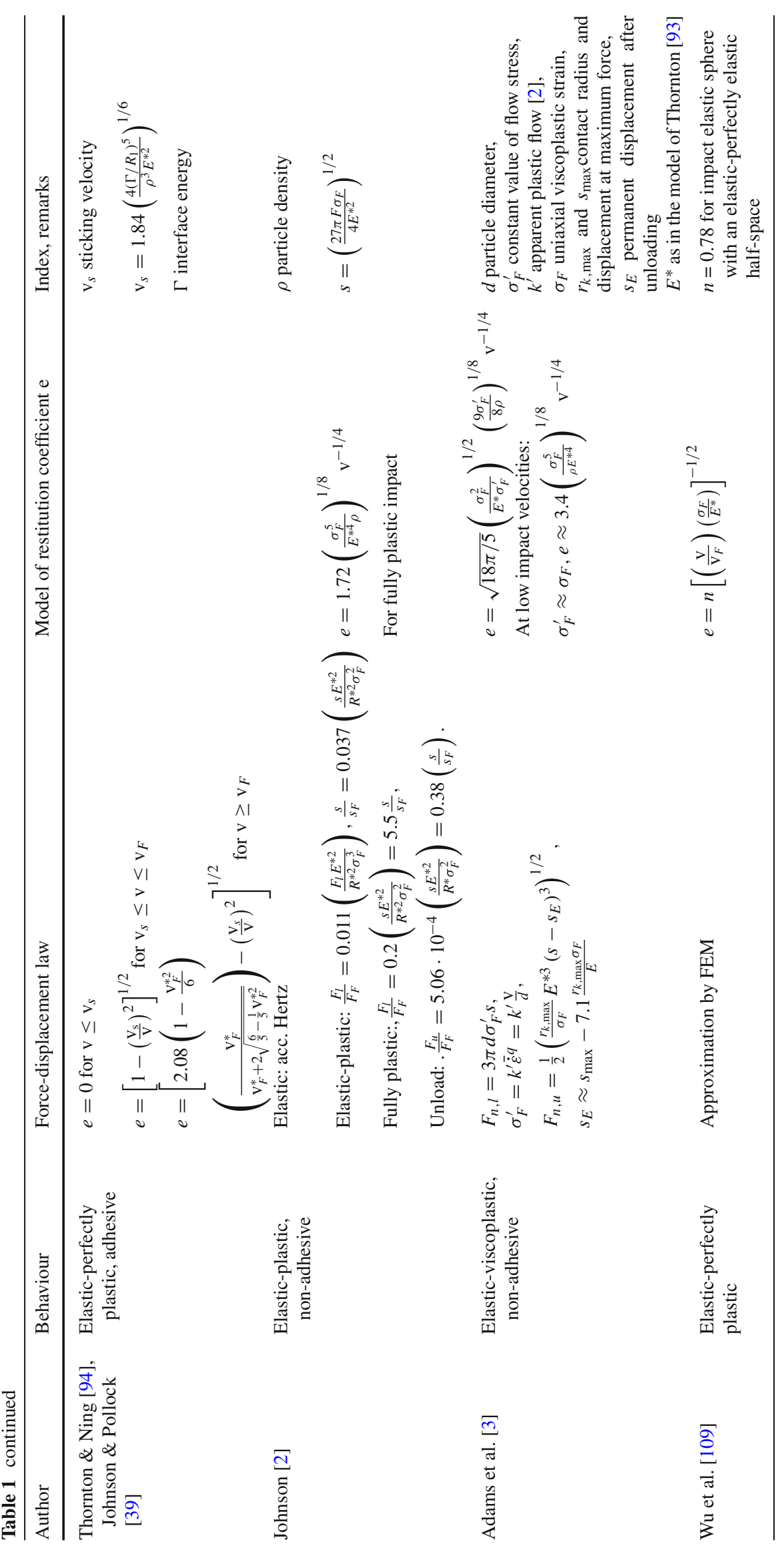




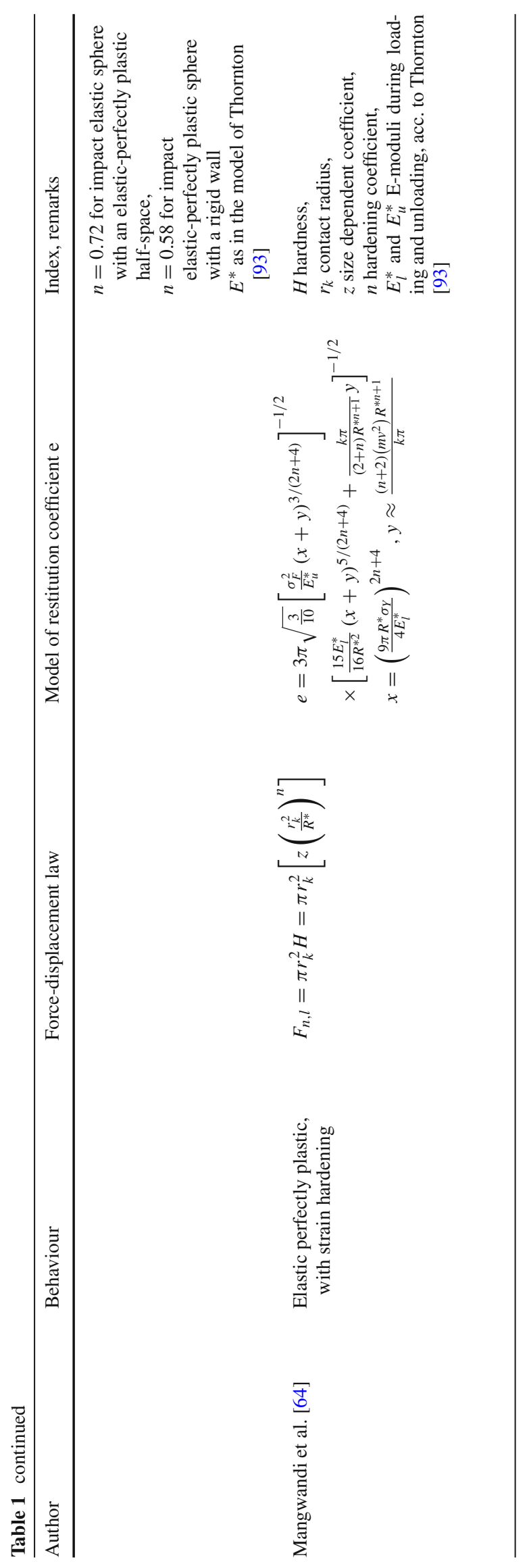




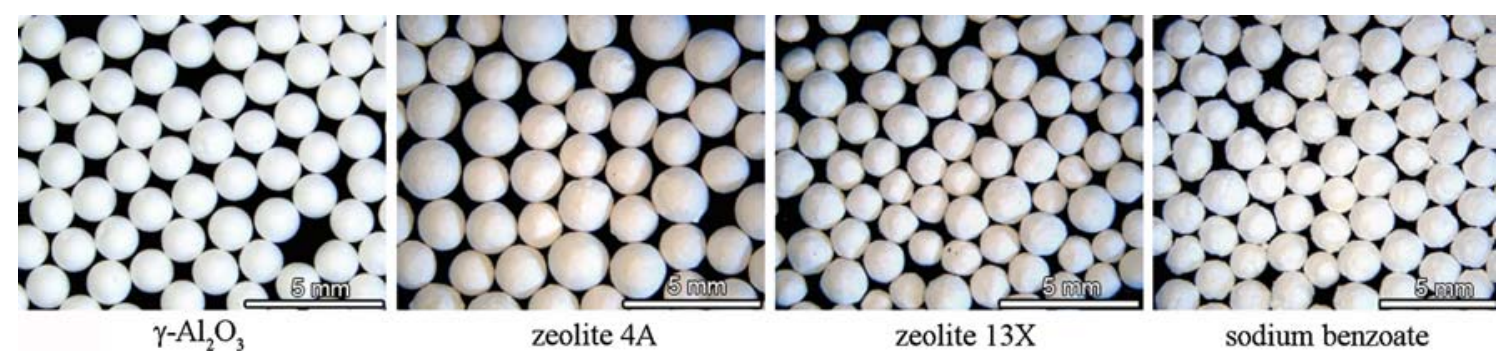

Fig. 11 Digital images of examined granules

Table 2 Characteristics of the examined granules

\begin{tabular}{|c|c|c|c|c|}
\hline Characteristics & $\gamma-\mathrm{Al}_{2} \mathrm{O}_{3}$ & Zeolite 4A & Zeolite $13 \mathrm{X}$ & Sodium benzoate \\
\hline Chemical composition in $\%$ & $97.9 \% \gamma-\mathrm{Al}_{2} \mathrm{O}_{3}$ & $\begin{array}{c}85 \% \text { Synthetic } \\
\text { zeolite 4A } \\
\text { binder: clay }\end{array}$ & $\begin{array}{c}85 \% \text { Synthetic } \\
\text { zeolite } 13 \mathrm{X} \\
\text { binder: clay }\end{array}$ & $\mathrm{C}_{6} \mathrm{H}_{5} \mathrm{CO}_{2} \mathrm{Na}$ \\
\hline Granule size in $\mathrm{mm}$ & $1.6-1.9$ & $2.1-2.5$ & $1.2-1.7$ & $0.86-0.96,1.24-1.60$ \\
\hline Sphericity & 0.95 & 0.91 & 0.94 & 0.92 \\
\hline Granule density in $\mathrm{kg} / \mathrm{m}^{3}$ & 1040 & 1140 & 1150 & 1440 \\
\hline Solid density in $\mathrm{kg} / \mathrm{m}^{3}$ & 3230 & 3640 & 2100 & 1500 \\
\hline Specific surface area in $\mathrm{m}^{2} / \mathrm{g}$ & 145 & 159 & 415 & 7.6 \\
\hline Pore volume in $\%$ & 68 & 69 & 45 & 4 \\
\hline Water content in $\mathrm{kg}$ water $/ \mathrm{kg}$ solid & 0.023 & 0.002 & 0.006 & 0.007 \\
\hline Application & Drying processes & \multicolumn{2}{|c|}{$\begin{array}{l}\text { Adsorbent (molecular sieve) for drying } \\
\text { processes and cleaning of gas }\end{array}$} & Food and beverage preservative \\
\hline Manufacturer & Sasol, Hamburg & \multicolumn{2}{|c|}{$\begin{array}{l}\text { CWK Chemiewerk Bad Köstritz, Bad } \\
\text { Köstritz }\end{array}$} & DSM, Geleen \\
\hline
\end{tabular}

ficient. The compression and free-fall tests were performed at ambient temperature of $25^{\circ} \mathrm{C}$ and atmospheric pressure.

\subsection{Compression tests}

A compression test of a single particle up to primary breakage is used to determine the minimum energy requirement for breakage, as shown first by Carey and Bosanquet [14]. The absorption of stressing energy in particle bed crushing is much higher than in compression of a single particle because of friction between the particle contacts. In a compression test the secondary breakages (after the primary breakage) can be separately observed, due to the comparatively low deformation velocity (from $\mathrm{mm} / \mathrm{min}$ to $\mathrm{cm} / \mathrm{min}$ ).

In the pioneering works of Rumpf [77] and Schönert [80], the deformation and breakage behaviour of solid particles was described by force-displacement curves measured by compression tests. Recently, the granules have been investigated using compression test: $\mathrm{Al}_{2} \mathrm{O}_{3}$ produced by fluidized bed-spray granulation [4], detergents [78], enzyme [10], polymer bound $\mathrm{Al}_{2} \mathrm{O}_{3}$ granules [84] and calcium carbonate [64].

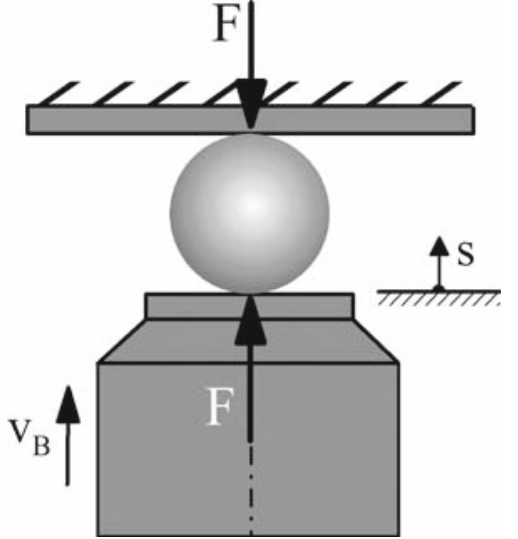

Fig. 12 Principle of single particle compression test

Figure 12 shows the principle of a granulate compression test. During the movement of the punch towards the upper fixed plate, a contact between the particle and the fixed plate is created. During the stressing period, displacement and force values are measured. Compression tests are carried out either with strain control (constant stressing velocities) or stress control (fixed stress or load rate). 
Because of fatigue of solids during the cyclic loading their breakage can occur at stresses that are substantially lower than the failure stress during static loading. The reduction of fracture strength occurs because of formation and propagation of shear zones and microcracks during each cycle. The number of cycles up to fracture decreases with increasing stress amplitude, which was already described for metallic and ceramic materials with the Wöhler curve [76]. The investigations of solid particles and agglomerates demonstrate the considerable effect of repeated loading on the mechanical behaviour and breakage point. Tavares and King [92] explained a decrease of the elastic-plastic stiffness of particles during repeated impacts as well as their breakage because of the formation and propagation of damages. In opposition to this, the stiffness of spherical granules increased with increasing number of loading/unloading compression cycles up to the point that saturation of the plastic deformation is reached [5]. The intensity and the frequency of stressing, the particle size and the microstructure influence material resistance against cyclic loading. Beekman et al. [10] and Pitchumani et al. [71] have also confirmed these effects for different granules.

During a repeated compression test, the punch moves towards the upper plate and presses the granule up to a defined force. Subsequently, the punch moves downwards, thus the unloading of the granule takes place.

The compression tests of the model granules performed in this work were repeated 100 times for each sample at a constant stressing velocity of $0.02 \mathrm{~mm} / \mathrm{s}$ to increase the statistical significance of results.

\subsection{Apparatus and methods for free-fall experiments}

Figure 13 shows the experimental setup for the free-fall experiments. Before it is dropped, a granule is held at a height $h_{1}$ above the target (flat plane) with the aid of vacuum tweezers. The granule falls freely onto a target and reaches a rebound height $h_{1, R}$ after the impact. The movement of the granule near the contact point before and after the impact is recorded by a high-speed video camera with a frequency of 4.000 frames per second and a resolution of $512 \times 256$ pixels.

From the ratio of energies in Eq. (43), it follows that the coefficient of restitution is a ratio of relative rebound velocity $\mathrm{v}_{1, \mathrm{R}}$ to that before impact $\mathrm{v}_{1}$. These velocities were determined from captured impacts in free-fall experiments with help of self programmed software on the basis of Matlab.

In order to examine the influence of the impact velocity on the restitution coefficient of granules, the drop height was varied from $12 \mathrm{~mm}$ to $1.5 \mathrm{~m}$, i.e. the impact velocity was in the range of about $0.5-4.5 \mathrm{~m} / \mathrm{s}$. This range was selected according to two criteria. The upper limit had to be below the critical impact velocity that leads to the breakage of gran- ules. In previous work [6] a critical velocity of $6.1 \mathrm{~m} / \mathrm{s}$ for zeolite $13 \mathrm{X}$ was found through impact tests. The performed measurements showed that the standard deviations of the impact and rebound velocities increase with increasing in the fall height. On the other hand, at heights below $12 \mathrm{~mm}$ the error of measurement greatly increases. Therefore the lower limit of the used impact velocities corresponds to the rebound velocitywhich can still be measured accurately.

During the free-fall tests, the angle of incidence $\Theta$ was varied from $0^{\circ}$ to $80^{\circ}$. To describe the oblique impact the angle $\Theta_{R}$ and angular velocity $\omega_{1, R}$ of granules after rebound from the wall have been measured. To detect the relatively small granules, a black background was installed.

For accurate measurement of the normal restitution coefficient normal impact and rebound should be ensured. During our experiments some granules without initial spin falling at normal impact rebounded of the horizontal plate under an angle $\left(0^{\circ}-10^{\circ}\right)$. This can be explained by the non-ideal spherical shape of the granules. Furthermore, the rebound behaviour of granules can be affected by defects of particle surface [6] when they occur in the contact range. However, during data processing no influence on the mean restitution coefficient was observed for rebound angles below $8^{\circ}$. Therefore, we determined the coefficient of restitution using freefall tests, in which the rebound took place in this small angle range. The free-fall test was repeated for each model material until 50 nearly vertically rebounds (angle below $8^{\circ}$ ) were captured. The number of valid measurements was about $80 \%$ for $\gamma-\mathrm{Al}_{2} \mathrm{O}_{3}, 30 \%$ for zeolites $13 \mathrm{X}$ and $4 \mathrm{~A}$ and $20 \%$ for sodium benzoate.

Neglecting the air resistance acting on the granule the restitution coefficient can be calculated as the ratio of drop and rebound heights in Eq. (43). However, provided that the height is large and the granule has a small density, the air resistance decreases the velocity of the particle greatly, which leads to a significant error in the restitution coefficient calculated through the heights.

The real velocity $\mathrm{v}_{1}$ of a free falling granule can be calculated depending on granule and air properties from the following force balance or equation of motion (also see Fig. 13):

$m_{1} \frac{d \mathrm{v}_{1}}{\mathrm{~d} t}=n\left(F_{g}-F_{B}\right)-F_{D}, n=\left\{\begin{array}{ll}1 & \text { fall } \\ -1 & \text { rebound }\end{array}\right.$,

where $m_{1}$ is the mass of granule, $F_{g}$ is the gravity force, $F_{B}$ is buoyancy force and $F_{D}$ is drag force.

For an ideally spherical granule with diameter $d_{1}$, and density $\rho_{1}$ Eq. (47) becomes:

$\mathrm{m}_{1} \frac{\mathrm{dv}_{1}}{\mathrm{dt}}=\mathrm{n} \frac{\pi \mathrm{d}_{1}^{3}}{6} \mathrm{~g}\left(\rho_{1}-\rho_{\mathrm{f}}\right)-\mathrm{c}_{\mathrm{D}} \frac{\pi \mathrm{d}_{1}^{2}}{4} \frac{\rho_{\mathrm{f}} \mathrm{v}_{1}^{2}}{2}$,

where $c_{D}$ is the drag coefficient and $\rho_{f}$ is air density.

The drag coefficient can be calculated according to Kaskas [43], which is applicable over the entire range of Reynolds 
Fig. 13 The schematic representation of free-fall device

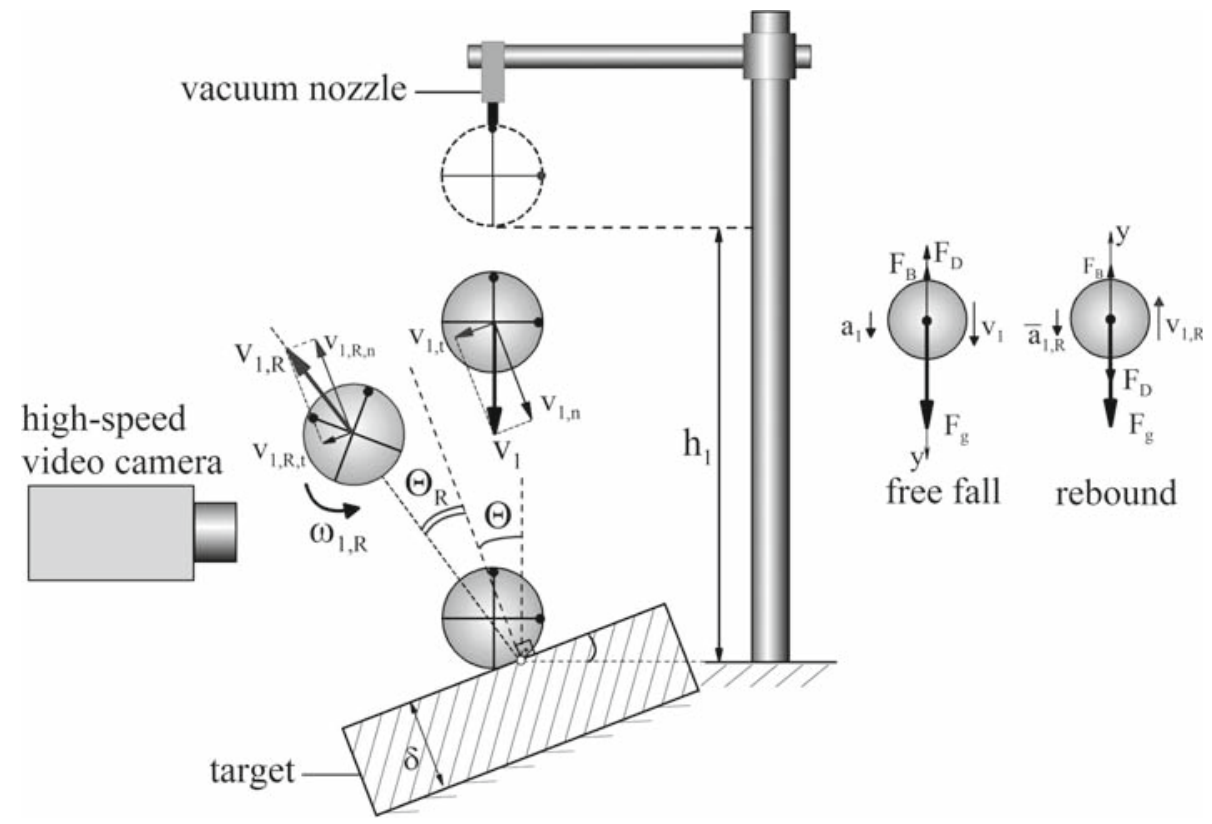

numbers $\left(0<\operatorname{Re}<2-4 \times 10^{5}\right)[81]$ :

$c_{D}=\frac{24}{R e}+\frac{4}{\sqrt{R e}}+0.4$,

where the particle Reynolds-number $R e$ is given by:

$R e=\frac{\mathrm{v}_{1} \mathrm{~d}_{1} \rho_{\mathrm{f}}}{\eta_{\mathrm{f}}}$,

where $\eta_{f}$ is dynamic viscosity of air.

The impact and rebound velocities of the examined granules were obtained by numerical solution of Eq. (48) using the drag coefficient from Eq. (49) (at $\eta_{f}=1.8 \times 10^{-5} \mathrm{~kg} / \mathrm{ms}$ and $\left.\rho_{f}=1.19 \mathrm{~kg} / \mathrm{m}^{3}\right)$ and the material properties from Table 2 . An example of the results is shown in Fig. 14 for $\gamma-\mathrm{Al}_{2} \mathrm{O}_{3}$ granules. A noticeable difference between the velocities calculated with and without air resistance and buoyancy forces can be observed at the heights above $0.2 \mathrm{~m}$. Hence, the large particle deceleration during fall and rebound due to mainly air resistance (the buoyancy force can be neglected with respect to the gravity, $\rho_{f}<<\rho_{1}$ ) confirmed that the drag cannot be neglected in this case. In our free-fall experiments mentioned below, the real velocities of the granules were observed by high-video recording of the impacts. The measured results (included in Fig. 14 for $\gamma-\mathrm{Al}_{2} \mathrm{O}_{3}$ ) confirmed the calculation for all examined granules.

Another point that must be considered to accurately measure the restitution coefficient is the energy absorption due to stress waves. Elastic stress waves arisen in the contact area can have significant effects on the restitution coefficient [48]. At the beginning of contact deformation, the spherical elastic wave expands away from the contact region into the target. After the reflection from target borders, the wave comes back

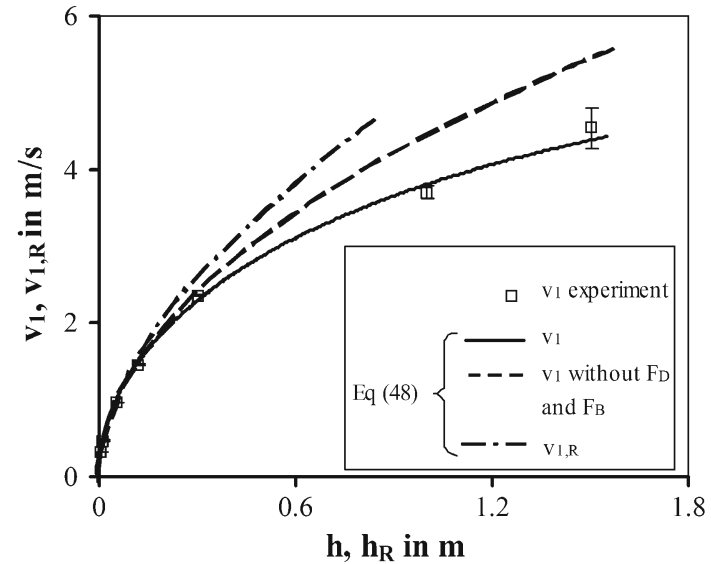

Fig. 14 Comparison between measurement and calculation of impact and rebound velocities at different drop heights for $\gamma-\mathrm{Al}_{2} \mathrm{O}_{3}$ granules ( $d_{1}=1.8 \mathrm{~mm}$ in calculation and $d_{1}=1.6-1.9 \mathrm{~mm}$ in experiments $)$

towards the contact area. If the contact time is longer than the period of wave propagation through the plate from contact point to the bottom wall of plate and return to the contact point then the waves will reach the contact partners and lead to loss of kinetic energy which was first calculated by Hunter [33]. Because of reflected waves the granule looses additional energy which leads to a decrease of the restitution coefficient. Koller [48] estimated this energy loss to about 3.6\% for a steel ball impacted on a glass plate with the thickness of $19 \mathrm{~mm}$.

Thus, the thickness $\delta$, width $B$ and length $L$ of the used target must be sufficiently large to exclude the energy absorption due the reflected elastic waves:

$\delta>\frac{\mathrm{v}_{l} \times t_{R}}{2}, B, L \geq \frac{\mathrm{v}_{t} \times t_{e l}}{2}$. 
The propagation speed of longitudinal $\left(\mathrm{v}_{l}\right)$ and transversal $\left(\mathrm{v}_{t}\right)$ waves through the target can be calculated from modulus of elasticity $E_{2}$, Poisson's ratio $\nu_{2}$ und density $\rho_{2}$ of the target [56]:

$$
\begin{aligned}
\mathrm{v}_{l} & =\left[\frac{E_{2}\left(1-v_{2}\right)}{\rho_{2}\left(1+v_{2}\right)\left(1-2 v_{2}\right)}\right]^{1 / 2}, \quad \mathrm{v}_{t}=\left[\frac{E_{2}}{2 \rho_{2}\left(1+v_{2}\right)}\right]^{1 / 2} \\
& =\left[\frac{G_{2}}{\rho_{2}}\right]^{1 / 2} .
\end{aligned}
$$

As target during the free-fall experiments a hardened steel plate $\left(E_{2}=2.1 \times 10^{5} \mathrm{~N} / \mathrm{mm}^{2}, v_{2}=0.25, \rho_{2}=7,850 \mathrm{~kg} / \mathrm{m}^{3}\right)$ with a smooth surface was used. In this material the longitudinal waves propagate at a velocity of $\mathrm{v}_{l}=5,367 \mathrm{~m} / \mathrm{s}$ and a transversal wave velocity of $\mathrm{v}_{l}=3,626 \mathrm{~m} / \mathrm{s}$. The time of impact $t_{R}$ in Eq. (51) can be estimated using Eq. (17) taking into account the properties of the granules mentioned below (see Tables 2 and 3). Finally, the minimal thickness of the target was found to be $21 \mathrm{~mm}$. Since the behaviour of granules is not ideally elastic, the time of contact is higher than calculated using Hertz theory. Therefore, for the experiments a target thickness of $30 \mathrm{~mm}$ was employed. The width and length of the plate $(210 \mathrm{~mm})$ are less important, since the transversal wave with $\mathrm{v}_{t}<0.64 \times \mathrm{v}_{l}$ is relatively slow.

\section{Experimental results}

\subsection{Material parameters}

The typical force-displacement curve for $\gamma-\mathrm{Al}_{2} \mathrm{O}_{3}$ granules is shown in Fig. 15. At the beginning of the punch-particle contact the elastic contact deformation of the granule takes place. The elastic force was described by Hertz theory, Eq. (10). The modulus of elasticity and stiffness of the granule during elastic deformation were calculated from Eqs. (4) and (11), respectively. The average values of the mechanical properties of the examined granules are summarised in Table 3.

Due to the initial parabolic curvature of $F(s)$, the contact stiffness increases with increasing displacement and reaches the maximum value in the yield point $F$ in Fig. 15. In this point the plastic deformation begins. This is confirmed by the increasing deviation of the experimental curve F-B from the theoretical Hertz curve (Fig. 15 right).

The slope of the curve F-B is a measure of the elasticplastic stiffness, which is proportional to the granule radius and the yield strength, according to Eq. (30). A small slope of the curve implies more plastic behaviour, whereas a large slope indicates "stiff" material behaviour. In Eq. (26), the yield strength $p_{F}$ can be characterized as the beginning of the plastic displacement $s_{F}$ at contact force $F_{F}$. These parameters were determined from the force-displacement curves 
Fig. 15 Typical force-displacement curve of $\gamma \mathrm{Al}_{2} \mathrm{O}_{3}$ granules $\left(d_{1}=1.62-1.76 \mathrm{~mm}\right)$ during compression $\left(\mathrm{v}_{B}=0.02 \mathrm{~mm} / \mathrm{s}\right)$
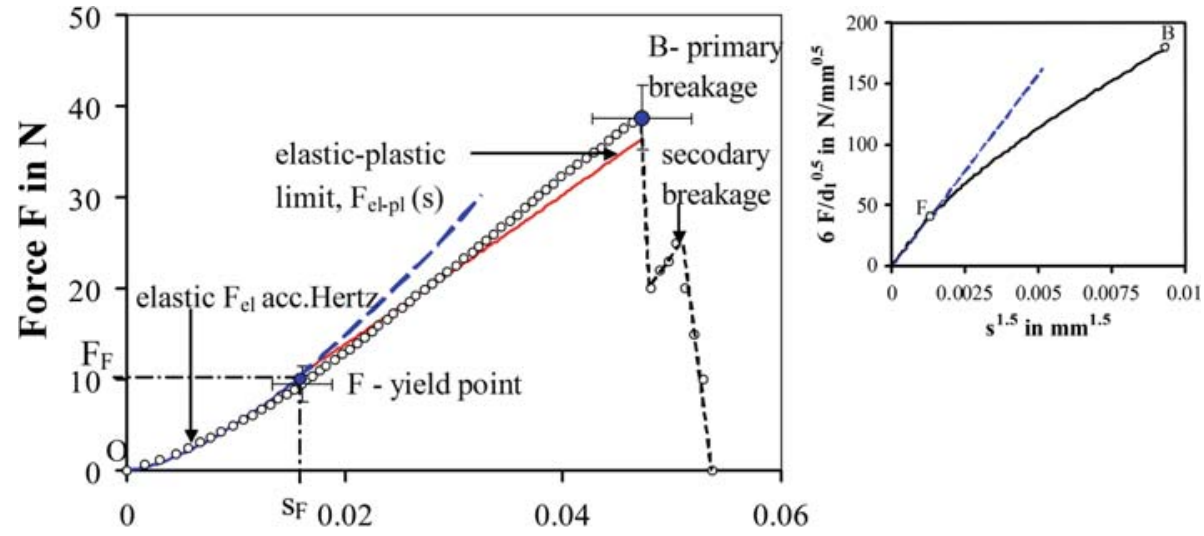

Displacement $\mathrm{s}$ in $\mathbf{m m}$

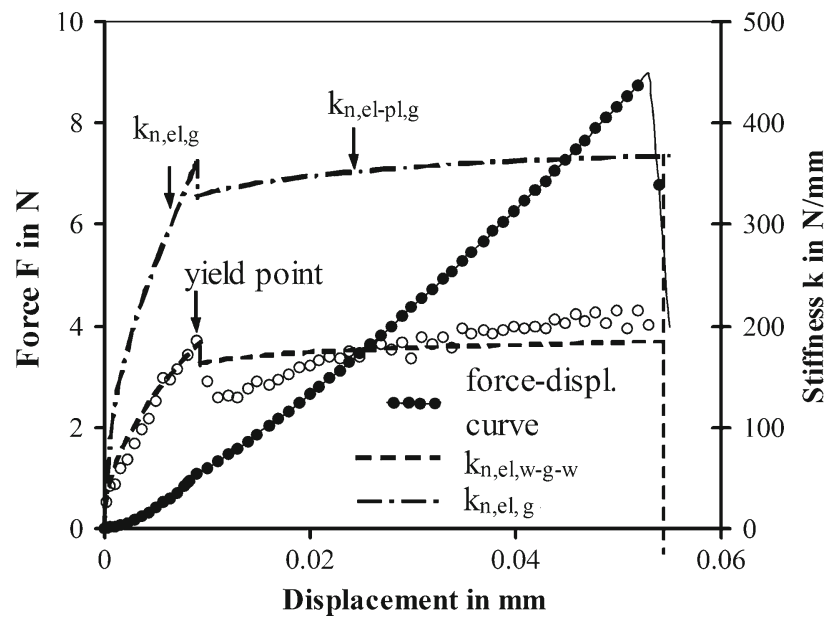

Fig. 16 Comparison of calculated and measured contact stiffness versus displacement of a typical zeolite $13 \mathrm{X}$ granule $\left(d_{1}=1.4 \mathrm{~mm}\right)$ at compressive stress $\left(\mathrm{v}_{B}=0.02 \mathrm{~mm} / \mathrm{s}\right)$

(Table 3) and thereby the force in elastic-plastic deformation range was approximated. The small deviation of the theoretical curve from experimental data is explained by the fact that the contact area of the granule under compression was not perfectly circular and had visible roughness (Fig. 18) [5].

The contact stiffness of a granule during elastic-plastic deformation (listed in Table 3) was calculated using Eq. (30) taking into consideration that $k_{n, e l-p l, g}=2 \times$ $k_{n, e l-p l, w-g-w}$. The force-displacement curve changes in the yield point from the elastic to the elastic-plastic range. Therefore, the contact stiffness drops at this point. Fig. 16 shows the development of the stiffness during the full deformation range of a zeolite $13 \mathrm{X}$ granule. After a severe decrease in yield point the stiffness gradually decreases during the elastic-plastic deformation up to the breakage point where the stiffness suddenly drops. It is noted here that the elasticplastic stiffness of $\gamma \mathrm{Al}_{2} \mathrm{O}_{3}$ and both zeolite granules exceeds their peak values at the yield point.

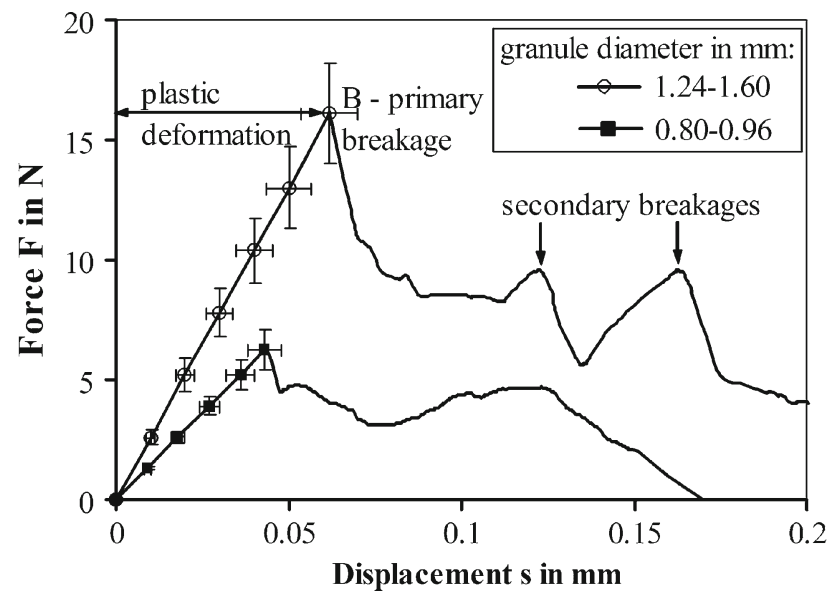

Fig. 17 Typical force-displacement curves of sodium benzoate granules during compression $\left(\mathrm{v}_{B}=0.02 \mathrm{~mm} / \mathrm{s}\right)$

Using the elastic-plastic contact area coefficient $\kappa_{A}$ in Table 3 the amount of plastic deformed contact area $A_{p l}$ in comparison to the total contact area can be observed. Close to the breakage point the coefficient $\kappa_{A}$ of $\gamma-\mathrm{Al}_{2} \mathrm{O}_{3}$ and zeolite $13 \mathrm{X}$ reaches the value of $\sim 4 / 5$. According to Eq. (22) this result corresponds to a contact area ratio of $A_{p l} / A_{K}=2 / 5$.

The breakage of the $\gamma-\mathrm{Al}_{2} \mathrm{O}_{3}$ granule follows at a force (point $\mathrm{B}$ in Fig. 15), which is approximately three times higher than the yield force (point F). Compared to this, the zeolite 13X granule shows a small elastic deformation (Fig. 16), but considerable elastic-plastic deformation before primary breakage.

The force-displacement curve of sodium benzoate is a straight line along the whole deformation region up to the breakage (Fig. 17). According to Eq. (35), that means that perfectly plastic deformation occurs when $A_{e l}=0$ and $A_{K}=A_{p l}$. Figure 17 shows the effect of the granule size on the force-displacement behaviour. In the case of bigger plastic granules, both the breakage force and the contact stiffness increase. The stiffness of zeolite granules in elastic and elas- 
Table 4 The contact radius and yield pressure of sodium benzoate granules by compression

\begin{tabular}{|c|c|c|c|c|c|c|}
\hline \multirow[t]{2}{*}{ Granule diameter $d_{1,50}$ in $\mu \mathrm{m}$} & \multirow[t]{2}{*}{$\mathrm{s}_{\mathrm{B}}$ in $\mu \mathrm{m}$} & \multicolumn{2}{|c|}{$d_{k, p l}\left(\right.$ at $\left.s_{p l}=40 \mu \mathrm{m}\right)$ in $\mu \mathrm{m}$} & \multirow[t]{2}{*}{$r_{k, p l}$ at $s_{B}$ in $\mu \mathrm{m}$} & \multirow[t]{2}{*}{$p_{F}$ in $\mathrm{MPa}$} & \multirow[t]{2}{*}{$\sigma_{\max }$ in $\mathrm{MPa}$} \\
\hline & & Eq. (34) & Experiment & & & \\
\hline $870 \pm 61$ & $43 \pm 6$ & 264 & $245 \pm 14$ & $136 \pm 14$ & $114 \pm 20$ & $10.5 \pm 1.8$ \\
\hline $1390 \pm 90$ & $66 \pm 8$ & 333 & $308 \pm 18$ & $215 \pm 20$ & $112 \pm 21$ & $10.7 \pm 1.7$ \\
\hline
\end{tabular}

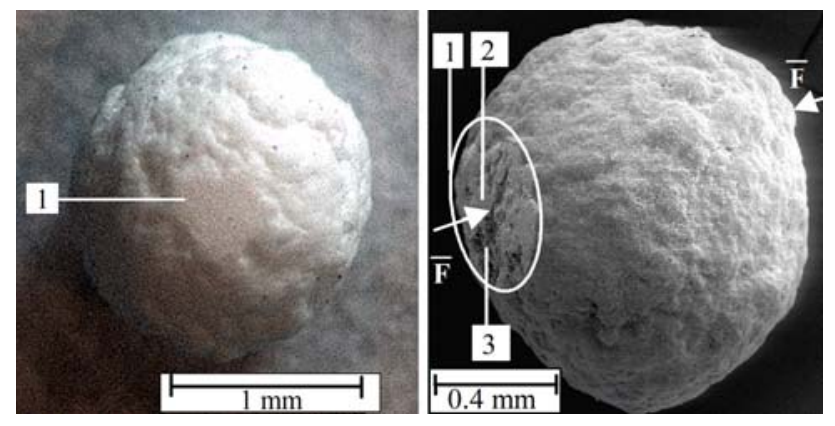

Fig. 18 SEM of flattened surface of a sodium benzoate granule after the compression test: 1 the entire approximated circular contact area, 2 the real contact area, 3 less deformed part of a contact surface (roughness depressions)

tic-plastic ranges increases with increasing granule diameter and therefore the material becomes stiffer, see Eqs. (11) and (30). The increase in the breakage force does not influence the material strength of plastic granules, $\sigma_{\max }=F_{B} /\left(\pi R_{1}^{2}\right)$. As an example - for different size fractions of sodium benzoate (see Table 4) the average compressive strength is about 10.6 MPa. Eqs. (34) and (35) can be used to develop the equation for the strength of dominantly plastic granules:

$\sigma_{\text {max }}=\frac{s_{B}}{R_{1}} p_{F} \approx 0.1 p_{F}$,

where $s_{B}$ is the displacement up to the primary breakage point. The constant ratio $s_{B} / R_{1}$ was experimentally found to be about 0.1 .

At the same deformation value, the formed contact area increases with increasing particle size. Figure 18 shows Scanning Electron Microscope (SEM) images of a sodium benzoate granule after the compression. The flattened contact surface (1) is not perfectly circular, since the granules surface is not evenly curved and contains roughness. Load and contact plastic deformation occur only at the asperities (2) of the contact. Therefore a small part of the area is not deformed (3).

The diameter of the contact $d_{k, p l}$ in Table 4 is calculated by Eq. (34) at a deformation value of $40 \mu \mathrm{m}$. This value is in good agreement with the equivalent contact area measured using a microscope. Each average value here corresponds to 10 SEM measurements. We have observed that the yield pressure $p_{F}$ is independent of the particle size.

\subsection{Loading-unloading behaviour of granules}

Typical loading-unloading curves of model granules are shown in Fig. 19. Loading and unloading were performed at a constant stressing velocity of $0.02 \mathrm{~mm} / \mathrm{s}$. To examine the effect of the stress intensity on the energy absorption, the maximum loading force was varied. After the first loadingunloading cycle (up to force in point $U_{1}$ in Fig. 19) the granule was carefully rotated on the punch, to load another range on the granule surface during the second loading-unloading cycle (up to a force in point $U_{2}$ ). The magnitude of the second maximum force was chose to be in the range of $90-95 \%$ of the average breakage force of corresponding granules.

After the complete unloading (points $E_{i}$ ) all granules showed a permanent deformation. Furthermore, during the time of 10 seconds a contribution of this deformation about $5 \%$ disappeared due to creeping $\left(E_{i} \rightarrow E_{i}^{\prime}\right)$. Note that the unloading curve of elastic-plastic zeolite and $\gamma \mathrm{Al}_{2} \mathrm{O}_{3}$ granules differs from the loading in the elastic range (Hertz curve) because of softening during the unloading. Therefore, the slope of the unloading curve, or in other words, the stiffness during unloading is evidently larger then that during the elastic loading. The nearly vertical unloading curves of sodium benzoate without elastic deformation prove the dominantly plastic behaviour of these granules during the compression.

The work done during the compression of the examined granules was calculated according to the above derived relations (38-40). The energy absorption due to viscoelastic and viscoplastic deformations is neglected in this calculation. The good agreement of the predicted values with experimental data can be obtained from Fig. 19 and Table 5.

\subsection{Effect of cycle number on the dissipative behaviour at a constant load amplitude}

Zeolite 13X and sodium benzoate granules were investigated by one-way cyclic compression tests. During the measurement, a granule was repeatedly loaded and unloaded with a constant velocity of $0.02 \mathrm{~mm} / \mathrm{s}$ up to constant maximum force, which is called the load amplitude. This force was set near the average breakage point of the respective granule.

Figure 20 shows the force-time curves for the first four cycles. The load amplitude $\left(F_{c y c}=F_{\max }\right)$, the mean force 


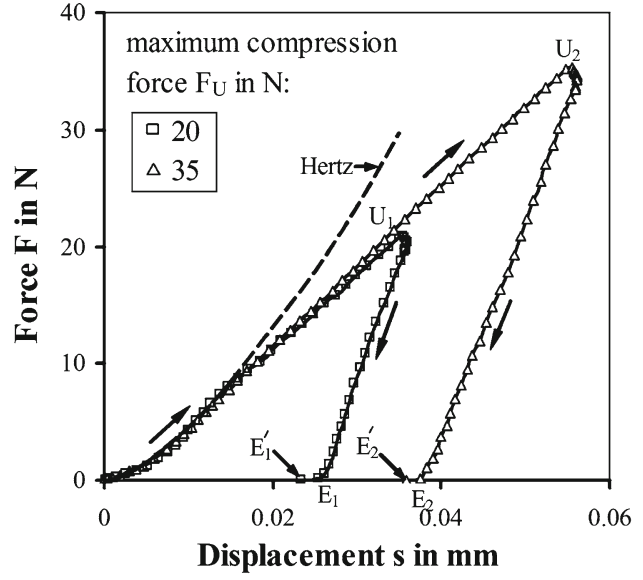

(a)

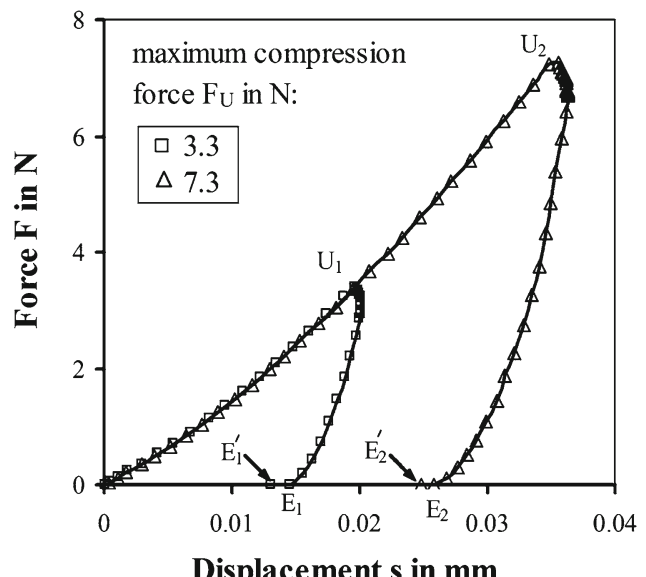

(c)

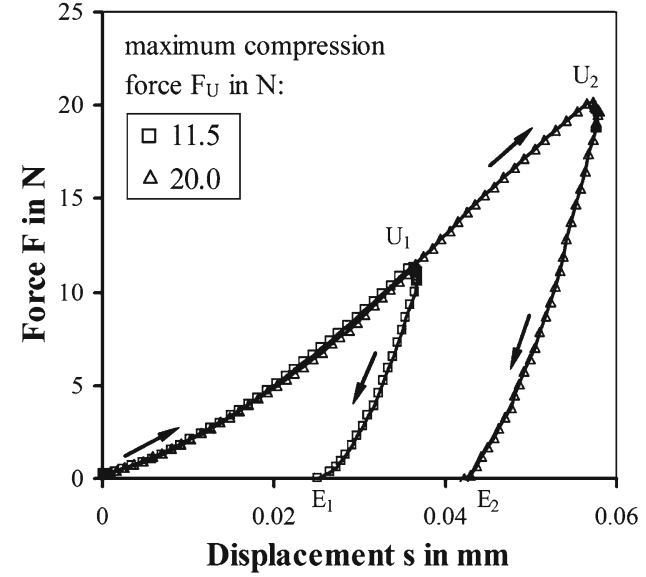

(b)

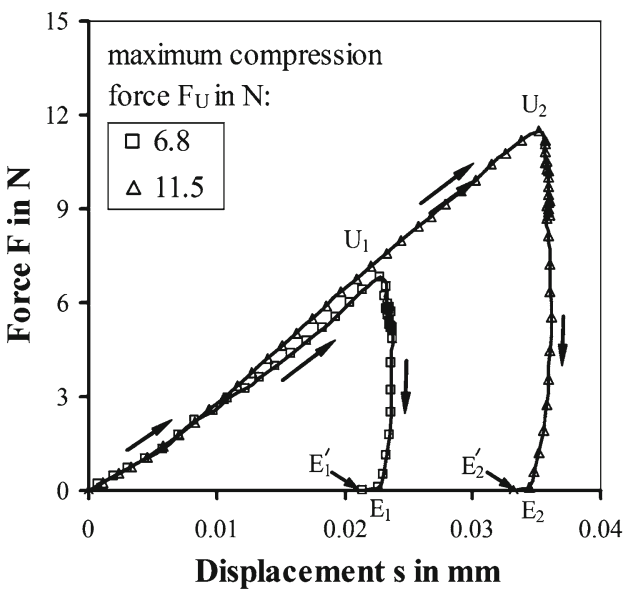

(d)

Fig. 19 Typical loading-unloading curves at different maximum compressive forces. a $\gamma \mathrm{Al}_{2} \mathrm{O}_{3}, d_{1}=1.67 \mathrm{~mm}$; $\mathbf{b}$ zeolite $4 \mathrm{~A}, d_{1}=2.10 \mathrm{~mm}$; c zeolite $13 \mathrm{X}, d_{1}=1.56 \mathrm{~mm}$ and $\mathbf{d}$ sodium benzoate, $d_{1}=1.60 \mathrm{~mm}$

Table 5 Energy characteristics of granule compression

\begin{tabular}{|c|c|c|c|c|c|c|c|c|}
\hline \multirow[t]{2}{*}{ Energy in $\mu \mathrm{J}$} & \multicolumn{2}{|c|}{$\gamma-\mathrm{Al}_{2} \mathrm{O}_{3}$ at $\mathrm{F}_{\mathrm{U}}=20 \mathrm{~N}$} & \multicolumn{2}{|c|}{ Zeolite $4 \mathrm{~A}$ at $\mathrm{F}_{\mathrm{U}}=20 \mathrm{~N}$} & \multicolumn{2}{|c|}{ Zeolite $13 \mathrm{X}$ at $\mathrm{F}_{\mathrm{U}}=7.3 \mathrm{~N}$} & \multicolumn{2}{|c|}{$\begin{array}{l}\text { Sodium benzoate } \\
\text { at } \mathrm{F}_{\mathrm{U}}=11.5 \mathrm{~N}\end{array}$} \\
\hline & Exp. & Theor. & Exp. & Theor. & Exp. & Theor. & Exp. & Theor. \\
\hline $\mathrm{W}_{\mathrm{el}, \mathrm{el}}$ & 44 & 48 & 329 & 345.2 & 5.2 & 4.8 & - & - \\
\hline $\mathrm{W}_{\mathrm{el}-\mathrm{pl}}$ & 311 & 310 & 162 & 172.9 & 111.9 & 112.7 & - & - \\
\hline $\mathrm{W}_{\mathrm{pl}}$ & - & - & - & - & - & - & 203 & 200 \\
\hline $\mathrm{W}_{\mathrm{L}}$ & 355 & 358 & 491 & 518.1 & 117.1 & 117.5 & 203 & 200 \\
\hline
\end{tabular}

$\left(F_{m}\right)$ and the period $(T)$ characterize the cyclic stressing process. As the number of cycles increases, the maximum force $F_{c y c}$ is reached faster. Thus, the cycle time decreases. After each unloading the testing device needed a time of $10 \mathrm{~s}$ for the reverse (pause $t_{u}$ in Fig. 20). The soft reversal of the equipment for the unloading leads to creep which can be seen after each peak in Fig. 20.
Figure 21 shows the results of a measurement by 20 cycles for a zeolite $13 \mathrm{X}$ granule. For clarity cycles from 3 to 18 were not included in this diagram. At the beginning of each cycle the granule behaves elastic only until the yield point $F$. If the loading curve of the second cycle $\left(E_{1} U_{2}\right)$ is moved to the approximated Hertz curve of the first cycle $\left(E_{1} \rightarrow E_{1}^{\prime}\right.$ in Fig. 21), it becomes clear that the second loading can be 


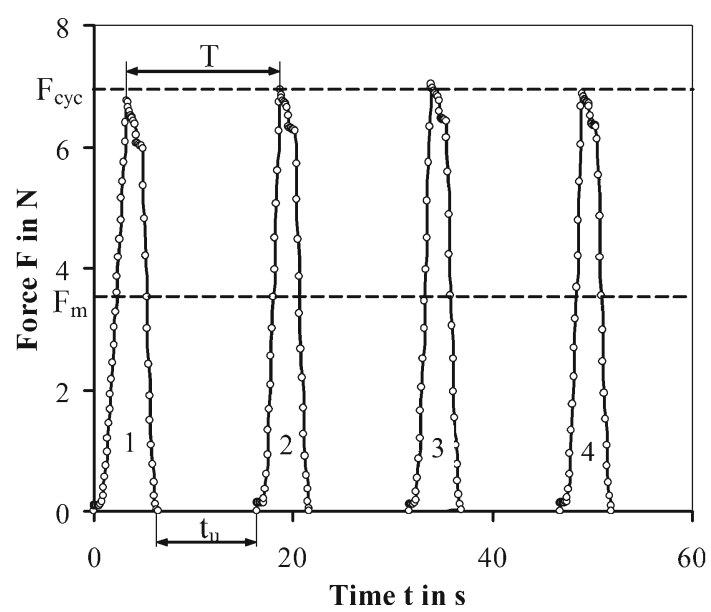

Fig. 20 Force-time curves during one-way cyclic loading in compression of a zeolite $13 \mathrm{X}$ granule $\left(d_{1}=1.54 \mathrm{~mm}, F_{c y c}=7 \mathrm{~N}, \mathrm{v}_{B}=\right.$ $0.02 \mathrm{~mm} / \mathrm{s}$ )

described by the Hertz equation of the first compression. Therefore, during each following loading the force-displacement response in elastic range depends on the modulus of the elasticity and on the amount of total plastic deformation accumulated in the previous cycles. The modulus of the elasticity remains nearly constant during the cyclic loading. Therefore it can already be determined during the first cycle. Considering these measurement results, the elastic force in cycle $z$ can be described with the force of the previous cycle $(z-1)$ :

$$
\begin{aligned}
F_{e l, z} & =F_{e l, z}\left(s_{e l, z}+s_{p l, z-1}\right)-F_{e l, z-1}\left(s_{p l, z-1}\right) \\
& =\frac{1}{6} E^{*} \sqrt{d_{1}}\left(\sqrt{\left(s_{e l, z}+s_{p l, z-1}\right)^{3}}-\sqrt{s_{p l, z-1}^{3}}\right) .
\end{aligned}
$$

The first derivative of the force-displacement function gives the stiffness of elastic deformation in cycle $z$ :

$k_{n, e l, w-g-w, z}^{*}=\frac{\mathrm{d} F_{e l, z}}{\mathrm{~d} s}=\frac{1}{4} E^{*} \sqrt{d_{1}\left(s_{e l, z}+s_{p l, z-1}\right)}$.

The loading curves obtained from Fig. 21 are shown in Fig. 22 in transformed coordinates according to Hertz equation (10), where $s_{z}$ is the displacement during a cycle $z$. The contact stiffness in the elastic and elastic-plastic deformation ranges increases with increasing number of cycles. The largest increase in the loading stiffness occurs by change from the first to the second cycle. A further increase of the curve slope can only be observed during the first 15 cycles. Therefore, all loading curves for $z>15$ are located on the same curve $O-U_{z}$, which approaches the corresponding Hertz curve practically up to the maximum force (point $U_{z}$ ). The hysteresis loops detected between unloading and reloading curves are gradually decreased with the progress of loading cycles. After some cycles no plastic deformation arises and the unloading curves return to the loading origin, i.e. a saturation state is reached. However, small viscoelastic deformations occur during the cyclic loading in the saturation state. As a result, the area of the hysteresis loop does not
Fig. 21 Typical loading-unloading curves during one-way cyclic loading in compression of zeolite $13 \mathrm{X}$ granule $\left(d_{1}=1.68 \mathrm{~mm}\right.$, $\left.F_{c y c}=7 \mathrm{~N}, \mathrm{v}_{B}=0.02 \mathrm{~mm} / \mathrm{s}\right)$

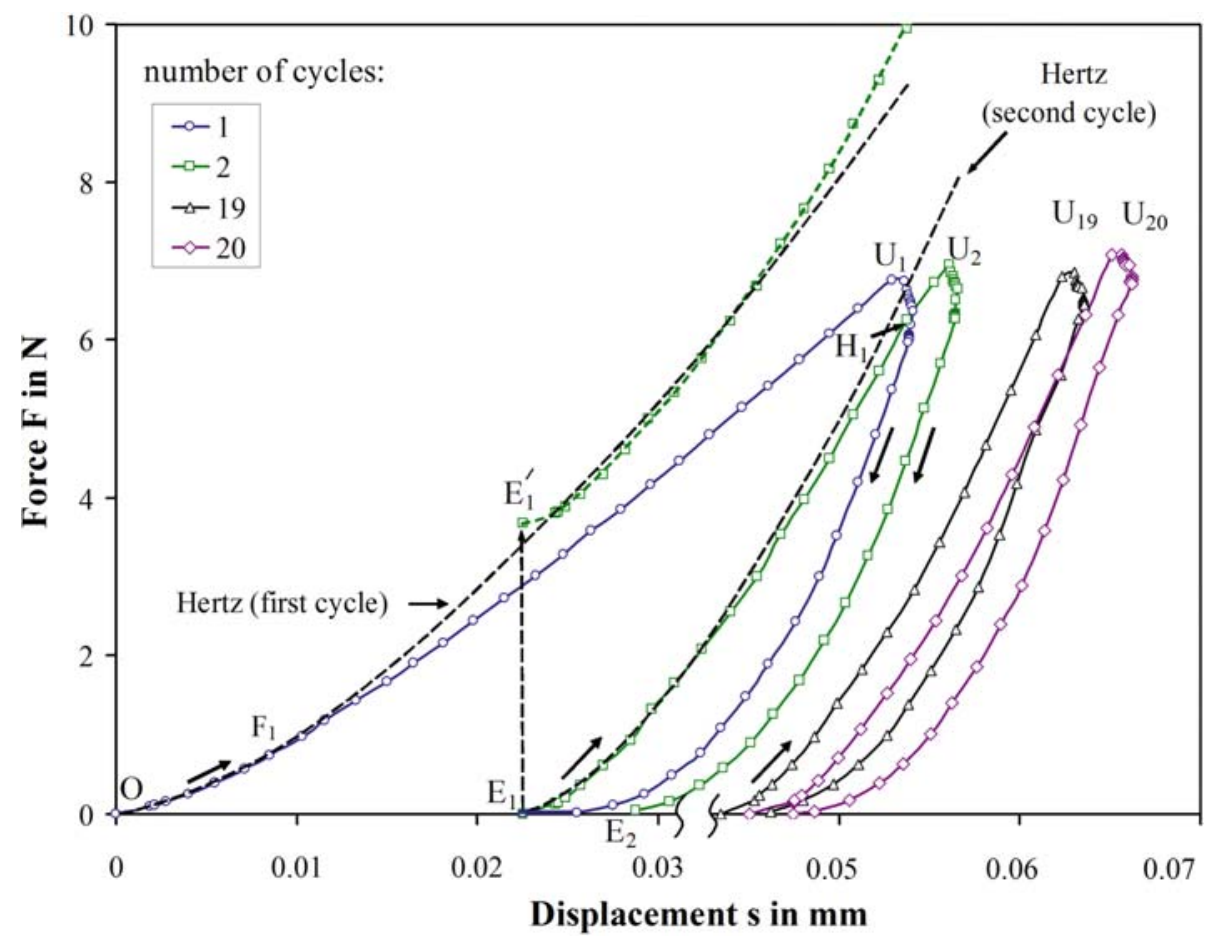


Fig. 22 Effect of number of loading-unloading cycles on contact stiffness of zeolite $13 \mathrm{X}$ granule $\left(d_{1}=1.68 \mathrm{~mm}, F_{c y c}=\right.$ $\left.7 \mathrm{~N}, \mathrm{v}_{B}=0.02 \mathrm{~mm} / \mathrm{s}\right)$

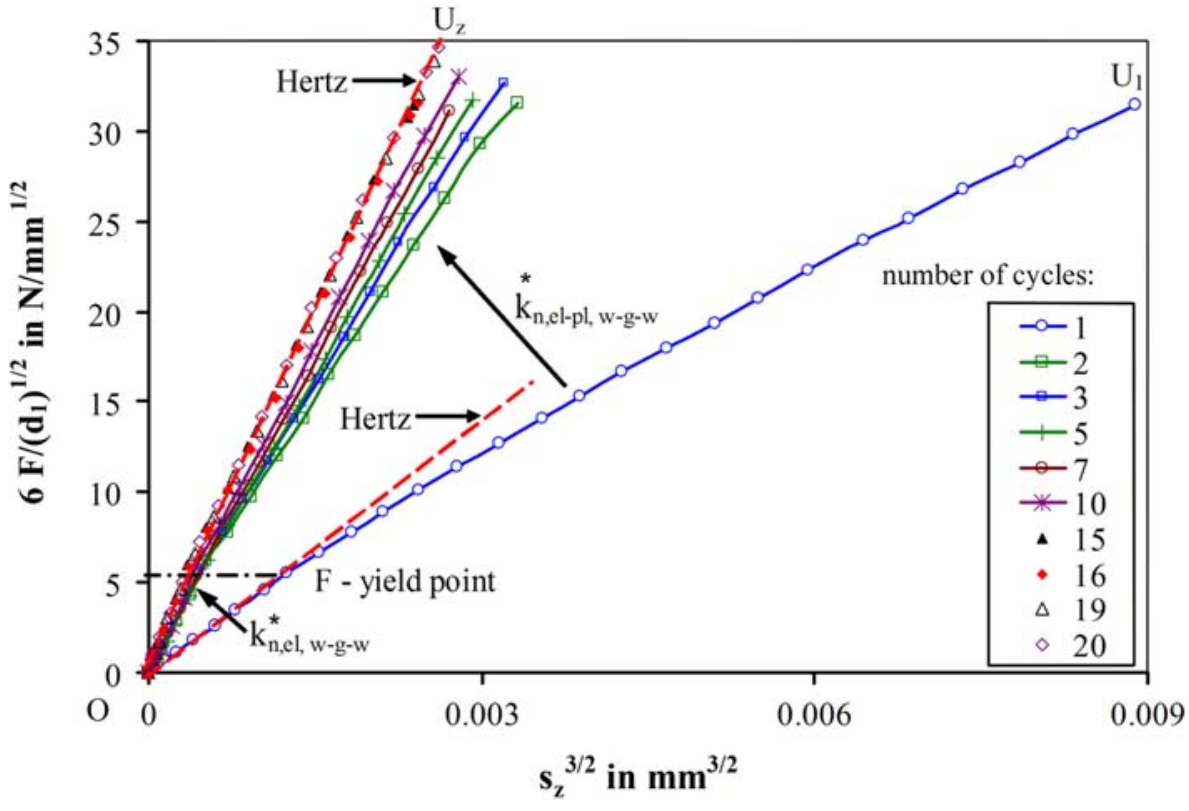

fully disappear; see the loop between the loading-reloading curves of the 19th and 20th cycles in Fig. 21.

From the curves $F\left(s_{z}\right)$ in Fig. 23 it can be observed that after 25 cycles the sodium benzoate granule deforms only viscoelastic without permanent deformation and so it exhibits the same loading-unloading response in all further cycles. Thus, the behaviour of both examined granules during cyclic loading changes from respectively elastic-plastic (by zeolite $13 \mathrm{X}$ ) and dominantly plastic (by sodium benzoate) to viscoelastic.

Figure 24 illustrates the development of elastic and plastic strains during the cyclic loading-unloading for the two examined granules. The increase of cycle number results in gradual decreasing the plastic strain to a zero value, which clearly indicates a cyclic hardening of granules and reaching a saturation state, at which the elastic behaviour becomes dominant. The maximum elastic strain remains constant at each cycle.

The cyclic hardening can be explained on the basis of microstructure change within the contact of the granule, since the highest compressive stresses are generated there. During the plastic deformation of the granule the structure is greatly deformed within the contact area (see Fig. 25). The largest changes occur at the first cycle, which is also shown in increasing slope of the loading curve from the first to the second cycle in Fig. 22 and 23. This microstructure change takes place locally close to contact zone, which was confirmed with the following experiment. After the first loading cycle we turned over $\left(90^{\circ}\right)$ the granule to stress two other contacts on the granule surface in the next cycle. The force-displacement curve measured in the second cycle exhibits the same slope as in the first cycle (Fig. 19).
The radius of plastic deformed contact area after unloading is the initial contact radius for the reloading. The total displacement and the contact radius in the cycle $z$ can be calculated according to:

$$
\begin{aligned}
s_{z}= & s_{p l, z-1}+s_{e l, z}+s_{p l, z}, r_{k, z}=r_{k, p l, z-1}+r_{k, e l, z}\left(s_{e l, z}\right) \\
& +r_{k, p l, z}\left(s_{p l, z}\right),
\end{aligned}
$$

where $s_{e l, z}$ is the elastic displacement at cycle $z\left(s_{e l, z}\right.$ lies in a range from 0 to the yield point $\left.s_{F}\right) \cdot s_{p l, z}$ is the plastic displacement in cycle $z \cdot s_{p l, z-1}$ is the total plastic contact displacement in previous cycles $(1 \ldots z-1), s_{p l, z-1}=\sum_{i=1}^{z-1} s_{p l, i}$,. Thereby, $s_{p l, z-1}$ characterises the history of the contact displacement.

The plastic displacement in cycle $z$ can be described for a cyclically hardening material with the following relationship:

$s_{p l, z}=s_{p l, 1} / z^{\alpha}$,

where $s_{p l, 1}$ is the plastic displacement in the first cycle. The exponent $\alpha$ represents a saturation parameter, which depends on the material properties and the cyclic force amplitude. Higher values of $\alpha$ correspond to the smaller number of cycles that are needed to approach the saturation state. The total plastic displacement in both contacts of compressed granule during $z$ cycles accumulates from the plastic displacements of individual cycles:

$s_{p l, t o t, z}=\sum_{i=1}^{z} s_{p l, i}$.

From the approximation according to Eq. (57) (Fig. 26) the following values of the saturation parameter were obtained: 
Fig. 23 Typical

loading-unloading curves during one-way cyclic loading in compression of sodium benzoate granule $\left(d_{1}=1.76 \mathrm{~mm}, F_{c y c}=\right.$ $16 \mathrm{~N}, \mathrm{v}_{B}=0.02 \mathrm{~mm} / \mathrm{s}$ )
Fig. 24 The elastic and plastic compressive strains versus the number of cycles: a zeolite $13 \mathrm{X}$, $d_{1}=1.68 \mathrm{~mm}, F_{c y c}=7 \mathrm{~N}$, b sodium benzoate, $d_{1}=1.76 \mathrm{~mm}, F_{c y c}=16 \mathrm{~N}$
Fig. 25 SEM of surface microstructure of a sodium benzoate granule before (a) and after (b) compression (contact area). One can see locally deformed primary particles, shear and frictional sliding between the contacts of the primary particles and formation of shear bands (1). This leads to energy absorption by friction
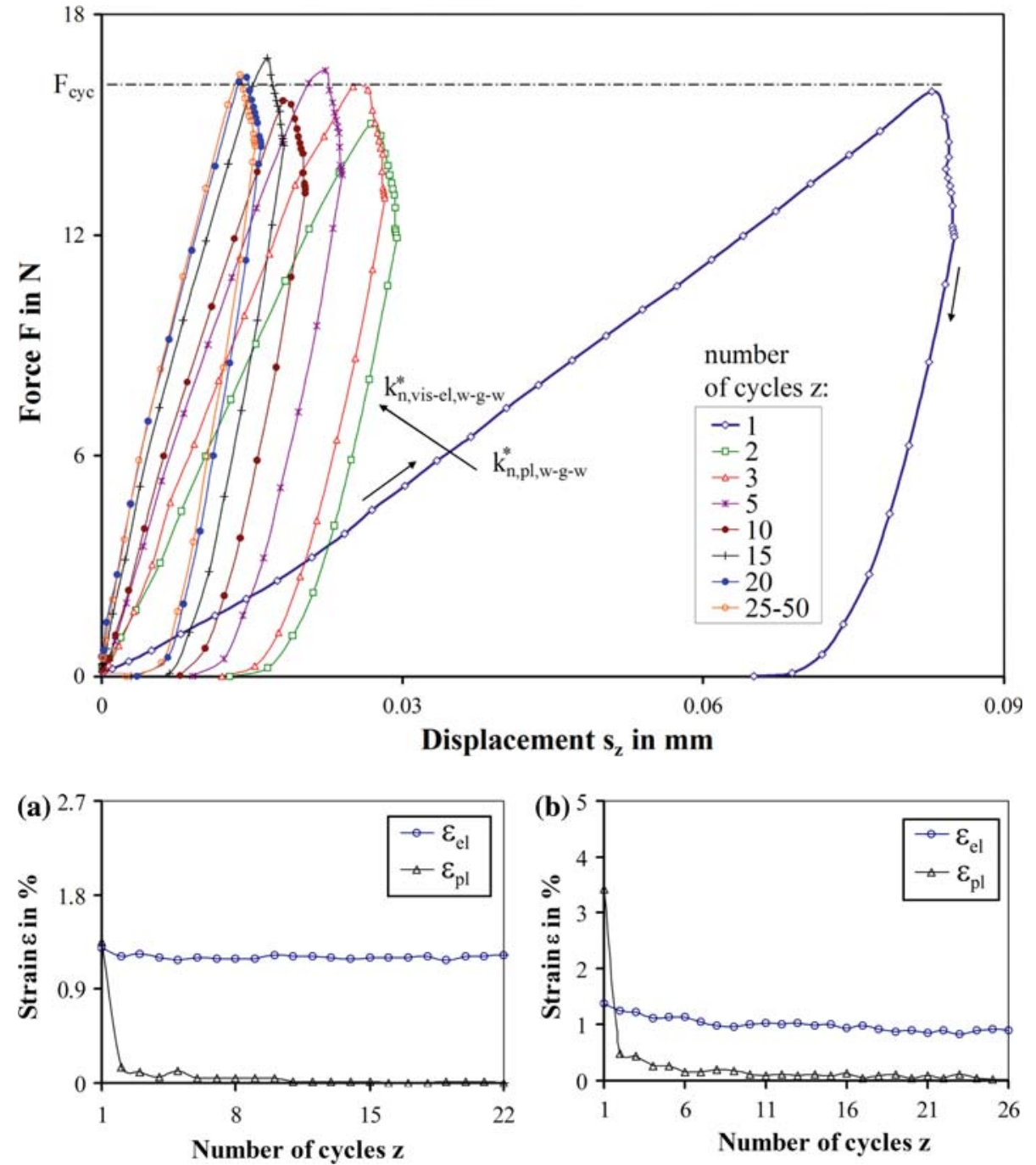

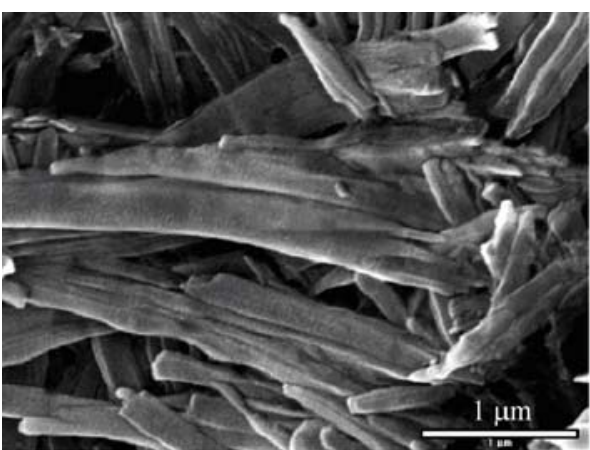

(a)

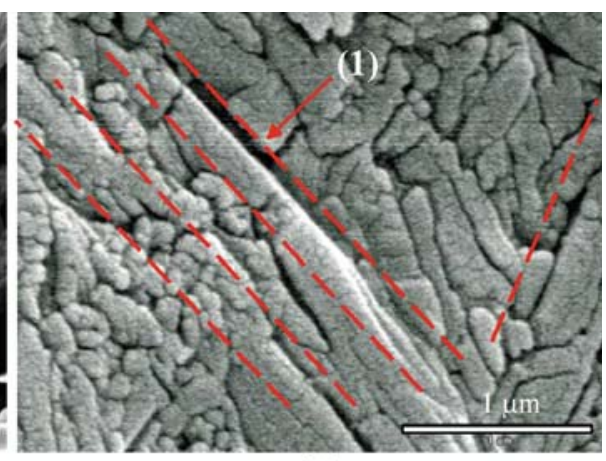

(b) $\alpha=2.0$ for zeolite granules and $\alpha=1.66$ for sodium benzoate granules. In addition to Fig. 24 the curves in Fig. 26 show the difference in the plastic displacement of both granules.

Combining Eqs. (56) and (57), the total displacement of the granule in a cycle $z$ can be written:

$s_{z}=s_{e l, z}+\sum_{i=1}^{z} \frac{s_{p l, 1}}{i^{\alpha}}$.
Substituting Eq. (59) into Eq. (11), we obtained the stiffness during the elastic displacement $s_{e l, z}$ at each cycle for more than two cycles:

$$
\begin{gathered}
k_{n, e l, w-g-w, z}=\frac{1}{4} E^{*} \sqrt{d_{1}\left(s_{e l, z}+\sum_{i=2}^{z}\left(\frac{s_{p l, 1}}{(i-1)^{\alpha}}\right)\right)}, \\
\text { by } z \geq 2, \mathrm{i} \in[2, \mathrm{z}] .
\end{gathered}
$$




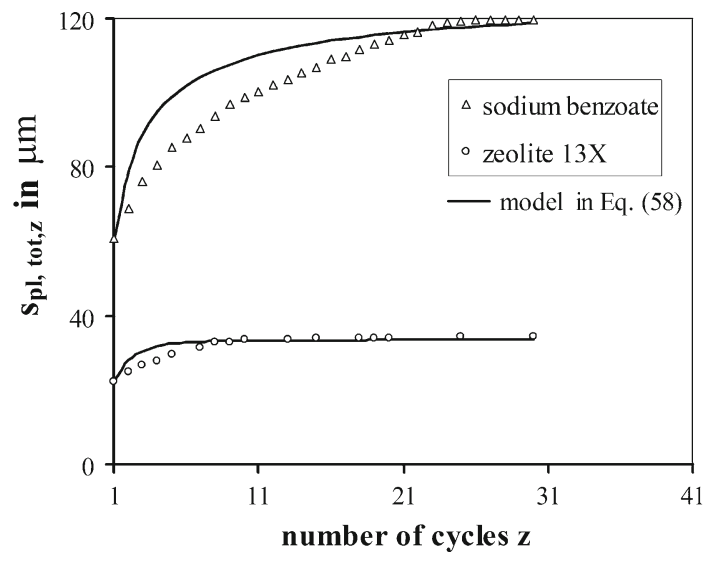

Fig. 26 The total plastic displacement of granules versus the number of one-way loading-unloading cycles (sodium benzoate: $d_{1}=1.76 \mathrm{~mm}$ at $F_{c y c}=16 \mathrm{~N}, \mathrm{v}_{B}=0.02 \mathrm{~mm} / \mathrm{s}$ and zeolite $13 \mathrm{X}: d_{1}=1.68 \mathrm{~mm}$ at $\left.F_{c y c}=7 \mathrm{~N} ; \mathrm{v}_{B}=0.02 \mathrm{~mm} / \mathrm{s}\right)$

Two parameters (the plastic displacement in the first cycle $s_{p l, 1}$ and saturation parameter $\alpha$ ) are needed to calculate the elastic stiffness in each cycle. The development of the contact stiffness during loading, unloading and reloading for a zeolite granule is plotted in Fig. 27. Due to increase of contact area the contact stiffness increases, see Eq. (8). The increase of the stiffness from the beginning of the first cycle to the yield point $\left(O_{1}-F_{1}\right)$ was calculated using Eq. (11) for elastic stiffness. In the same way, the above developed elastic-plastic model in Eq. (30) was used to approximate the stiffness after the beginning of the plastic deformation up to the point in which unloading starts $\left(F_{1}^{\prime}-U_{1}\right)$. At the beginning of unloading $\left(U_{1}^{\prime}\right)$ the stiffness is well higher than during loading. The stiffness decreases quickly to zero at the end of unloading. However, the development of the stiffness from the beginning of reloading to the yield point $\left(O_{2}-F_{2}\right)$ corresponds to the elastic deformation and it can be described with the model in Eq. (60) using the above obtained parameters: $\alpha=2.0, s_{p l, 1}=22 \mu \mathrm{m}$. Due to hardening of the granules the slope of the curve at the second cycle beyond the yield point $\left(F_{2}-U_{2}\right)$ is higher than at the first cycle.

The energy absorption during the static cyclic loading can be quantitatively expressed by an equivalent restitution coefficient. By analogy with impact stressing, it is the square root of the ratio of elastic strain energy $W_{e l}$ released during the unloading to the total deformation energy $W_{L}$, i.e. the work done by contact force during the compression of the granule:

$\mathrm{e}_{\mathrm{eq}}=\sqrt{\mathrm{W}_{\mathrm{el}} / \mathrm{W}_{\mathrm{L}}}$

Figure 28 shows the equivalent restitution coefficient of the granules as a function of the number of cycles obtained from the force-displacement curves of the above described

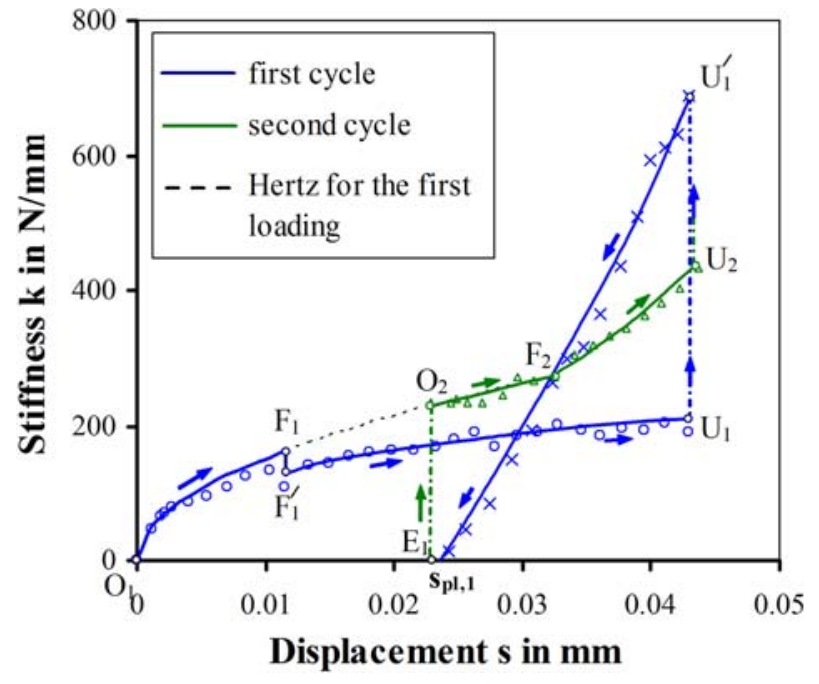

Fig. 27 Development of contact stiffness during the loading $\left({ }^{\circ}\right)$, unloading $(x)$ and reloading $(\triangle)$ of a zeolite $13 X$ granule according to the experiment in Fig. $21\left(d_{1}=1.68 \mathrm{~mm}, F_{c y c}=7 \mathrm{~N}, \mathrm{v}_{B}=0.02 \mathrm{~mm} / \mathrm{s}\right)$

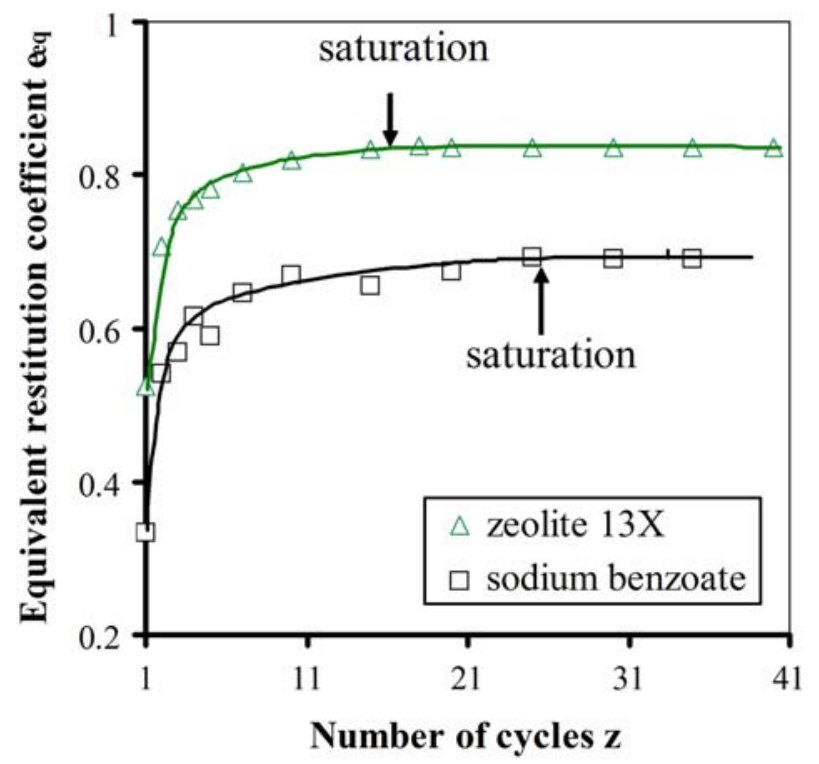

Fig. 28 Effect of repeated one-way cyclic loading on the equivalent restitution coefficient of the granules

cyclic tests. Due to the decrease of the deformation energy and energy absorption with increasing number of cycles, the equivalent restitution coefficient increases until a saturation state in the plastic deformation. It is evident that the increase of the restitution coefficient can also be shown during the repeated impact stressing of these granules on the same contact point. An example of this behaviour for brass spheres was presented by Weir and Tallon [108]. However, the restitution coefficient of some materials decreases with increasing impact number due to the softening, microcracking and breakage (see [92]). 
Fig. 29 The

force-displacement curves during the cyclic loading of a zeolite $13 \mathrm{X}$ granule $\left(d_{1}=\right.$ $\left.1.62 \mathrm{~mm}, \mathrm{v}_{B}=0.02 \mathrm{~mm} / \mathrm{s}\right)$. At each maximum compressive force $F_{U}$ five cycles were performed. For clarity, only the first cycle of each series is shown

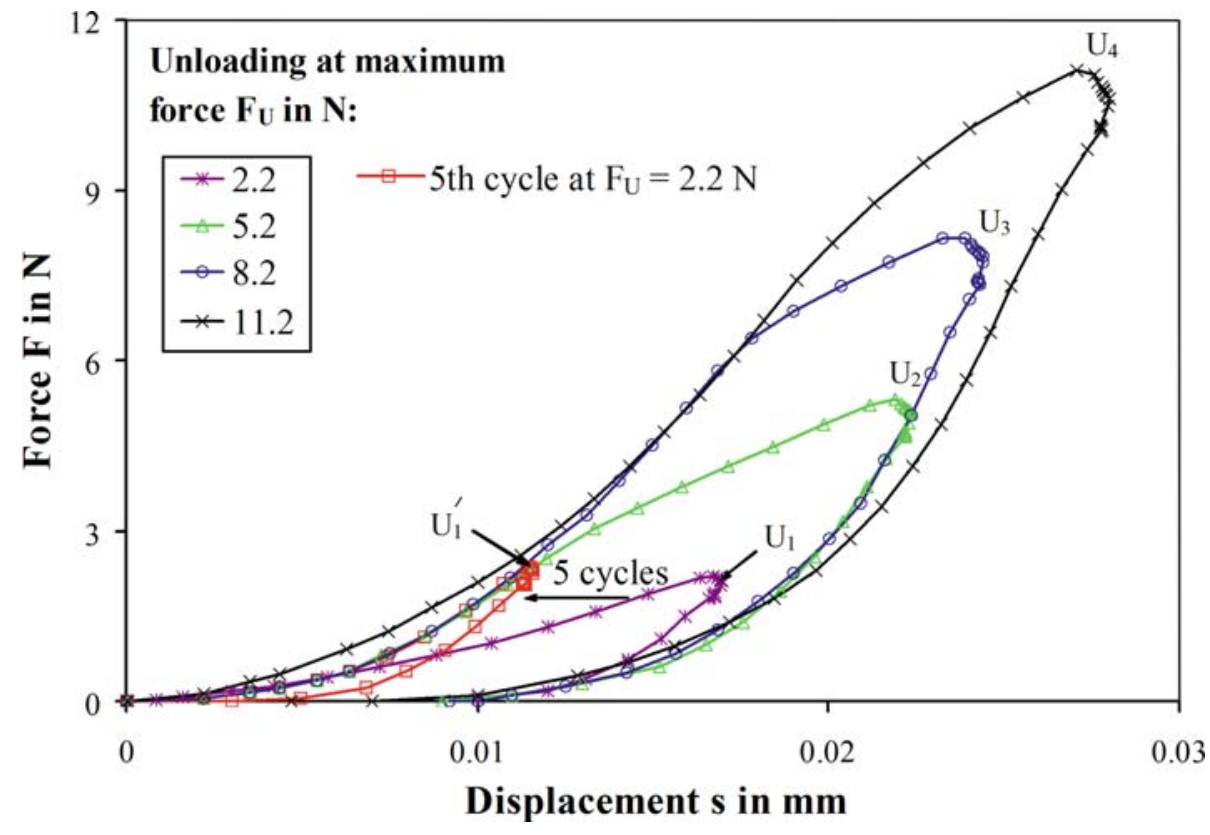

4.4 Dissipative behaviour during cyclic loading with increasing stressing intensity

In the previous section we discussed the behaviour of granules at cyclic loading up to a maximum force, which was kept constant in the test. In practice, the magnitude of the contact force acting on a granule in a bed, e.g. during fluidisation, pneumatic transportation, mixing, shows a distribution that depends on the process parameters. An estimation of the evolution of the average interparticle force during bed settling under gravity after fluidisation was performed using DEM in the publication of Moreno-Atanasio et al. [66].

In this section we describe how the behaviour of the granules changes with increasing the maximum cyclic force. A granule of zeolite $13 \mathrm{X}$ was first five times repeatedly compressed by a constant load amplitude of $2.2 \mathrm{~N}$. The next five cycles were performed at higher load amplitude of $5.2 \mathrm{~N}$. In the same way, the next cycles were carried out at a force of $8.2 \mathrm{~N}$ and subsequently at a force of $11.2 \mathrm{~N}$.

Figure 29 shows the force-displacement curves of the first cycles at the applied load amplitudes. With increasing number of cycles the slope of the loading curve increases (point $U_{1} \rightarrow U_{1}^{\prime}$ in Fig. 29) and the amount of plastic deformation decreases.

In the fifth cycle still a small plastic deformation occurs, since the zeolite $13 \mathrm{X}$ granules approach the saturation state after $\sim 15$ cycles. When we increased the force above $2.2 \mathrm{~N}$ in the sixth cycle the plastic deformation starts again which was detected after unloading by a significant increase in the irreversible deformation in comparison to the previous cycle. The inflection point at the maximum force of previ-

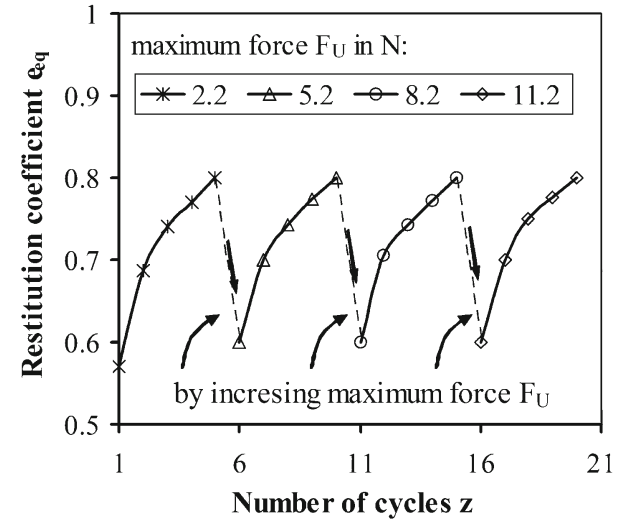

Fig. 30 Effect of number of cycles on the equivalent restitution coefficient of zeolite $13 \mathrm{X}$ granules by increasing load amplitude

ous cycle ( $U_{1}^{\prime}$ in Fig. 29) indicates clearly the transition to the plastic flow. During next cycles the slope of the loading curve changes only above this point.

It is noted here, that the loading curves of corresponding cycles at different load amplitudes are approximately parallel to each other in the plastic range, although four cycles between these loadings were performed. Thus the contact stiffness of the plastic deformation is independent of the maximum compressive force.

Furthermore, the curves showed that the previous cyclic loading at the lower force has no influence on the plastic deformation and saturation state in following cycles at a higher force. This assertion is confirmed by the equivalent coefficient of restitution in Fig. 30(A, B) obtained from forcedisplacement curves (also see Table 6 for the first cycles). 
Table 6 Energy balance of first loading-unloading cycle at different maximum forces

\begin{tabular}{lllll}
\hline $\mathrm{F}_{\mathrm{U}}$ in $\mathrm{N}$ & $\mathrm{W}_{\mathrm{L}}$ in $\mu \mathrm{J}$ & $\mathrm{W}_{\mathrm{L}} / \mathrm{m}_{1}$ in J/kg & $\mathrm{W}_{\mathrm{el}}$ in $\mu \mathrm{J}$ & $\mathrm{e}_{\mathrm{eq}}$ \\
\hline 2.2 & 14.7 & 5.7 & 4.8 & 0.57 \\
5.2 & 49.5 & 19.3 & 17.5 & 0.60 \\
8.2 & 80.7 & 31.5 & 29.0 & 0.60 \\
11.2 & 123.7 & 48.3 & 46.2 & 0.61 \\
\hline
\end{tabular}

\subsection{Free-fall tests}

\subsubsection{The coefficient of normal restitution}

The coefficients of normal restitution of the granules were obtained from the free-fall tests at different impact velocities using above described device (Fig. 13). All granules show the elastic-plastic impact behaviour in the examined velocity range, Fig. 31. Furthermore, the following sequence from elastic-plastic to dominantly plastic behaviour (based on the average coefficient of restitution) can be observed: $\gamma-\mathrm{Al}_{2} \mathrm{O}_{3}\left(e_{n}=0.735\right)$, zeolite $4 \mathrm{~A}\left(e_{n}=0.653\right)$, zeolite $13 \mathrm{X}\left(e_{n}=0.644\right)$ and sodium benzoate $\left(e_{n}=0.532\right)$. The same sequence of behaviour from elastic to plastic range was also shown by these granules during compression tests.

The standard deviations of the restitution coefficients measured by 50 repeated tests are relatively large. That was expected because of inhomogeneity of granules. For a given particle size, the contact stiffness and the position of the yield point are not constant, since the mechanical characteristics of the primary particles and the bonding agents are randomly distributed within a fraction of granules. The individual granules differ in surface roughness and distribution of sizes of pores. The standard deviation of the restitution coefficient corresponds to the standard deviation of contact stiffness obtained by compression tests of corresponding granules (Table 3).

For all four examined granules the increasing impact velocity in the examined range does not change the mean normal coefficient of restitution. In other words, the granules exhibit elastic-plastic behaviour without a viscous effect during the impact in this velocity range. As revealed previously by loading-unloading tests of these granules the magnitude of maximum load does not affect the ratio of energy absorption to the elastic strain energy. Under the assumption that the force-displacement behaviour during slow loading is approximately the same as during dynamic stressing, this can give a rational explanation for constant restitution coefficient.

The measured restitution coefficient was fitted with the model of Walton and Braun in Eq. (46), shown in Fig. 31 as horizontal lines. Using the measured values of contact stiffness during loading $\left(k_{L}=k_{n, e l, g}\right.$ for $\gamma-\mathrm{Al}_{2} \mathrm{O}_{3}$, zeolites and $k_{L}=k_{n, p l, g}$ for bigger fraction of sodium benzoate in

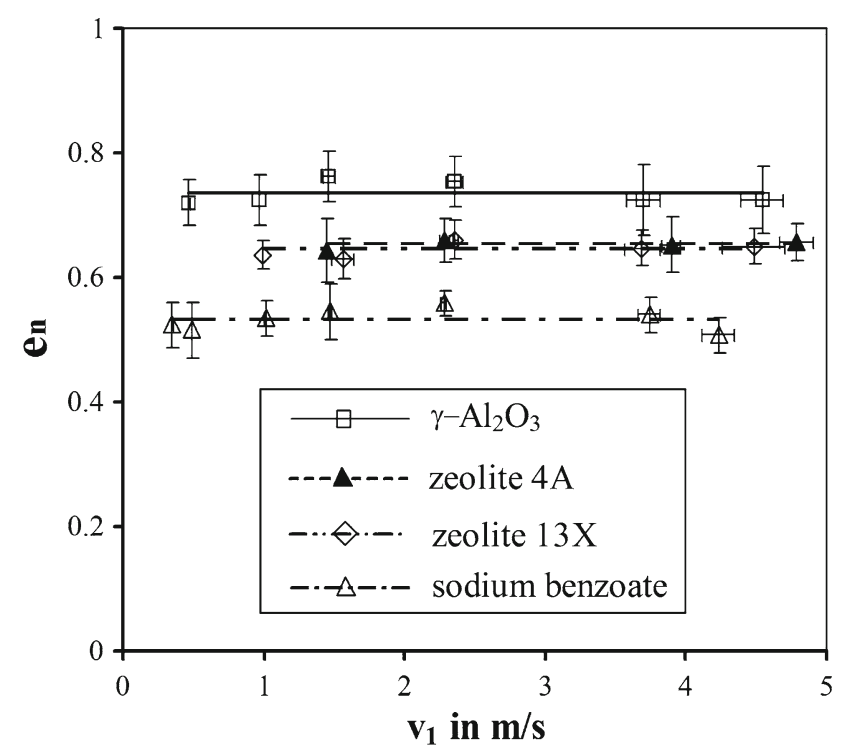

Fig. 31 Normal coefficient of restitution of examined granules versus impact velocity

Table 3), the stiffness during the unloading was determined as: $k_{U}=3,368 \mathrm{~N} / \mathrm{mm}$ for $\gamma-\mathrm{Al}_{2} \mathrm{O}_{3}, k_{U}=2,094 \mathrm{~N} / \mathrm{mm}$ for zeolite $4 \mathrm{~A}, k_{U}=636 \mathrm{~N} / \mathrm{mm}$ for zeolite $13 \mathrm{X}$ and $k_{U}=$ $1,736 \mathrm{~N} / \mathrm{mm}$ for sodium benzoate.

\subsubsection{Maximum impact force of the elastic, elastic-plastic and plastic granules}

From the free-fall experiments, we should estimate the maximum impact forces that act on the granule by impact and compare those with the yield point. Based on this information the conditions of the validity of Hertz theory to the performed impacts can be examined.

In the case of the impact of an elastic granule on a rigid wall the Eq. (20) can be simplified as:

$t_{e l, c r i t}=\frac{t_{e l}}{t_{w}}=1.43\left[\frac{m_{1}^{2} E_{1}^{1 / 2}\left(1-v_{1}^{2}\right)^{2}}{\mathrm{v}_{1} R_{1}^{6} \rho_{1}^{5 / 2}}\right]^{1 / 5}$.

The dependence of the critical impact time $t_{e l, c r i t}$ on the impact velocity $\mathrm{v}_{1}$ (Fig. 32) was calculated for three granules using the material properties from Table 3 . As has been 


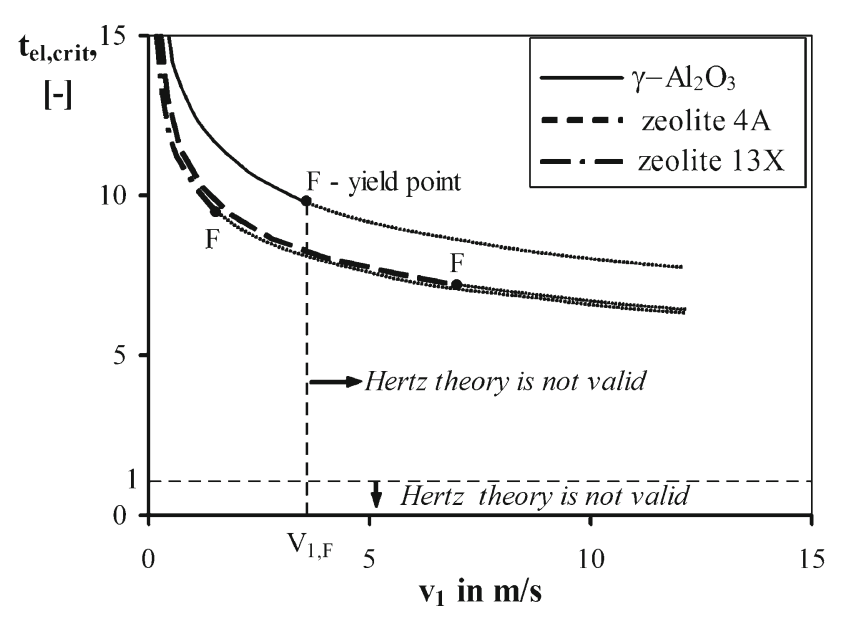

Fig. 32 Effect of the impact velocity $v_{1}$ of the granules on the critical impact time $t_{e l, c r i t}$

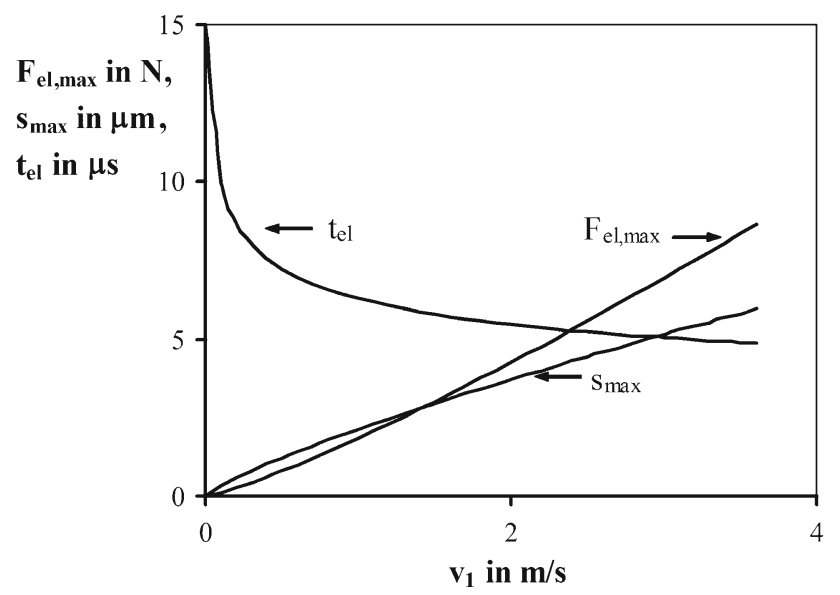

Fig. 33 Maximum displacement $\mathrm{s}_{\max }$, maximum force $\mathrm{F}_{e l, \max }$ and duration $\mathrm{t}_{e l}$ of the impact versus impact velocity $\mathrm{v}_{1}$ during the elastic impact of $\gamma-\mathrm{Al}_{2} \mathrm{O}_{3}$ granule on the steel wall

mentioned previously the elastic stress waves can show a visible influence only at high impact velocities $\left(\lim _{\mathrm{V}_{1} \rightarrow \infty} t_{e l}\right.$, crit $\rightarrow 1$ ). However, heretofore plastic deformation (point $F$ in Fig. 32) and breakage of granules occur. The minimum impact velocity $\left(\mathrm{v}_{1, F}\right.$ in Fig. 32$)$, at which the maximum impact force exceeds the yield point of the granule and the plastic deformation is initiated, can be determined according to Davies [17]:

$\mathrm{v}_{1, F}=\left(\frac{\pi p_{F}}{E^{*}}\right)^{2} \sqrt{\frac{2 p_{F}}{5 \rho_{1}}}$

Equations (15-17) can be used to calculate the maximum force, maximum deformation and duration of impact for velocities lower than $\mathrm{v}_{1, F}$ where the Hertz theory is valid. Figure 33 shows an example of the calculation for the $\gamma \mathrm{Al}_{2} \mathrm{O}_{3}$ granules.
In the case of elastic-perfectly plastic deformation behaviour of spherical granules, the maximum impact force can be calculated according to Thornton and Ning [94] as:

$F_{e l, p l, \max }=F_{F} \sqrt{\frac{6}{5} \frac{\mathrm{v}_{1}^{2}}{\mathrm{v}_{1, F}^{2}}-\frac{1}{5}}, \quad \mathrm{v}_{1} \geq \mathrm{v}_{1, F}$.

In this model the behaviour of the particle is assumed to be elastic at the beginning of loading and perfectly plastic after exceeding the yield point (index $e l, p l$ in Eq. 64), where the force $F_{F}$ at yield point is given by Eq. (28).

In the case of elastic-plastic deformation behaviour, beyond the yield point the centre of the contact area deforms plastically. But a ring at the periphery exhibits further elastic deformation. The maximum impact force can be calculated for an adhesive particle [100]:

$$
\begin{aligned}
& F_{e l-p l, \max }=\pi R^{*} p_{F}\left(\kappa_{A}-\kappa_{p}\right) \\
& \quad \times\left[\sqrt{\left(\frac{\kappa_{p} a_{F=0}}{2 \kappa_{A}}\right)^{2}+\frac{8 \rho_{1} R^{* 2}}{3 p_{F}}\left(\mathrm{v}_{1}^{2}-\mathrm{v}_{1, R}^{2}\right)+s_{F}^{2}}-\frac{\kappa_{p} a_{F=0}}{2 \kappa_{A}}\right] \\
& -F_{H 0},
\end{aligned}
$$

where $\kappa_{A}$ is the elastic-plastic contact area coefficient given in Eq. (23). $\mathrm{v}_{1}$ and $\mathrm{v}_{1, R}$ are the impact and rebound velocities, respectively. Neglecting the adhesion acting within the contact zone $\left(\kappa_{p}=0, F_{H 0}=0\right)$ and $s_{F}\left(\mathrm{~s}_{F}^{2} \rightarrow 0\right)$ the maximum force is given by:

$$
\begin{aligned}
F_{e l-p l, \max } & \approx \pi R_{1} p_{F} \kappa_{A} \sqrt{\frac{8 \rho_{1} R_{1}^{2}}{3 p_{F}}(1-e) \mathrm{v}_{1}} \\
& =\pi R_{1} p_{F} \kappa_{A} S_{e l-p l, \max } .
\end{aligned}
$$

Figure 34 shows the maximum force as a function of the impact velocity calculated for different deformation behaviour using models (16), (64) and (66). For this calculation the mean values of the material properties of $\gamma-\mathrm{Al}_{2} \mathrm{O}_{3}$ and zeolite 13X in Table 3 were used.

The yield point can be seen in Fig. 34 at the intersection of the curves for elastic and elastic-perfectly plastic behaviour at the impact velocity of $\mathrm{v}_{1, F}=1.7 \mathrm{~m} / \mathrm{s}$ for zeolite $13 \mathrm{X}$ and $\mathrm{v}_{1, F}=3.6 \mathrm{~m} / \mathrm{s}$ for $\gamma-\mathrm{Al}_{2} \mathrm{O}_{3}$. Comparing these values with the impact velocity of granules during the performed free-fall tests $\left(\mathrm{v}_{1}=0.5-4.5 \mathrm{~m} / \mathrm{s}\right)$ it is found that the zeolite granules exhibited the plastic deformation at drop heights above 0.15 $\mathrm{m}$ and the impact of $\gamma-\mathrm{Al}_{2} \mathrm{O}_{3}$ granules after the fall from the height below $1.0 \mathrm{~m}$ had to behave elastic. However, the measured restitution coefficients indicate the impact of these granules as elastic-plastic over the complete range of impact velocities, i.e. the energy absorption occurs also at low velocities and the yield point by collisional stressing is lower than by slow compression. 


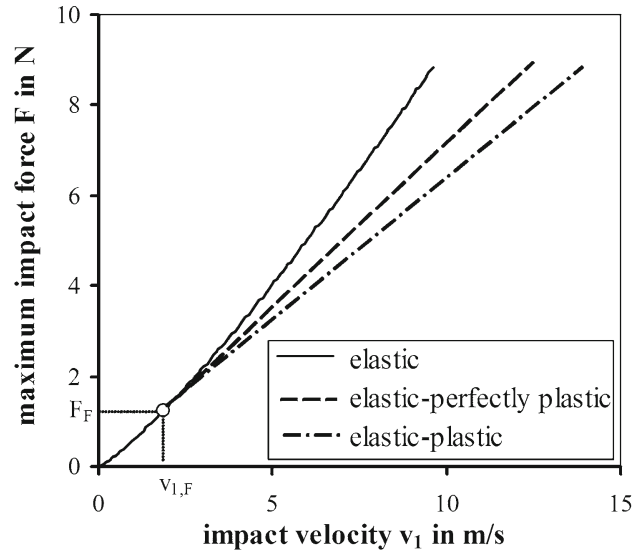

(a) zeolite $13 \mathrm{X}$ granule

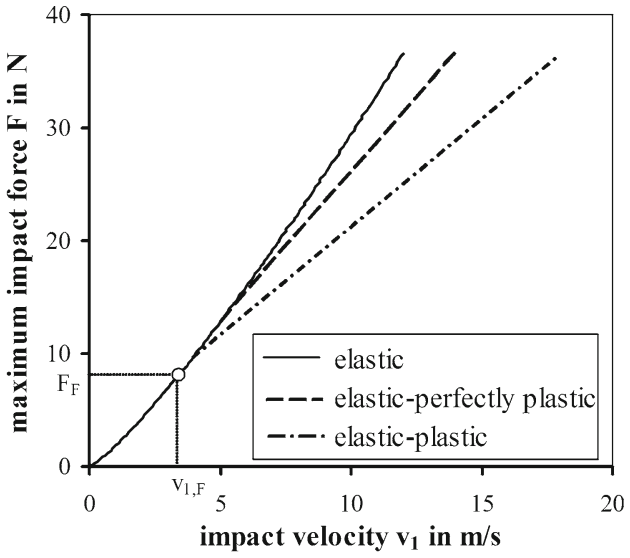

(b) $\gamma-\mathrm{Al}_{2} \mathrm{O}_{3}$ granule

Fig. 34 The maximum impact force versus impact velocity at different deformation behaviour of the granules

Table 7 Comparison of energy absorption by compression and impact

\begin{tabular}{|c|c|c|c|c|c|}
\hline \multirow[t]{2}{*}{ Granules } & \multirow[t]{2}{*}{ Diameter $d_{1,50}$ in $\mathrm{mm}$} & \multicolumn{2}{|l|}{ Impact } & \multicolumn{2}{|l|}{ Compression } \\
\hline & & $e_{n}$ & $\frac{\mathrm{W}_{\text {diss }}}{\mathrm{W}_{\text {kin }}, 1}$ & $e_{n, e q}$ & $\frac{W_{\text {diss }}}{W_{L}}$ \\
\hline$\gamma-\mathrm{Al}_{2} \mathrm{O}_{3}$ & $1.8 \pm 0.05$ & $0.735 \pm 0.018$ & 0.46 & $0.57 \pm 0.02$ & 0.68 \\
\hline zeolite 4A & $2.3 \pm 0.12$ & $0.653 \pm 0.007$ & 0.57 & $0.50 \pm 0.03$ & 0.77 \\
\hline zeolite $13 X$ & $1.4 \pm 0.05$ & $0.644 \pm 0.010$ & 0.59 & $0.52 \pm 0.06$ & 0.72 \\
\hline sodium benzoate & $1.7 \pm 0.11$ & $0.532 \pm 0.018$ & 0.72 & $0.11 \pm 0.03$ & 0.99 \\
\hline
\end{tabular}

\subsubsection{Comparison of the energy absorption by slow compression and rapid impact loading}

In comparison to the slow loading the same granules show higher restitution coefficients during impact (Table 7). During the impact the granules loose 15-27\% of energy less than during compression. It is independent of the impact velocity (in the range of $0.5-4.5 \mathrm{~m} / \mathrm{s}$ ) or on the maximum compression force.

\subsubsection{The tangential restitution coefficient}

In addition to the normal restitution coefficient measurement, the velocity of granules before and after the oblique impact has been measured with a high-speed camera to determine the tangential restitution coefficient (Eq. 45). To evaluate the angular velocity $\omega_{R}$ of granules at the rebound the granules were marked before testing, Fig. 35. The coefficient of tangential restitution was measured for $\gamma-\mathrm{Al}_{2} \mathrm{O}_{3}$, zeolite $4 \mathrm{~A}$ and sodium benzoate granules. The zeolite $13 \mathrm{X}$ granules were not examined as they have almost the same restitution coefficient as the zeolite $4 \mathrm{~A}$ granules.

The coefficient of restitution in the normal direction does not depend on the impact angle in the range from $0^{\circ}$ to $80^{\circ}$ in Fig. 36a. However, the coefficient of tangential restitution decreases with target inclination and reaches a minimum at an

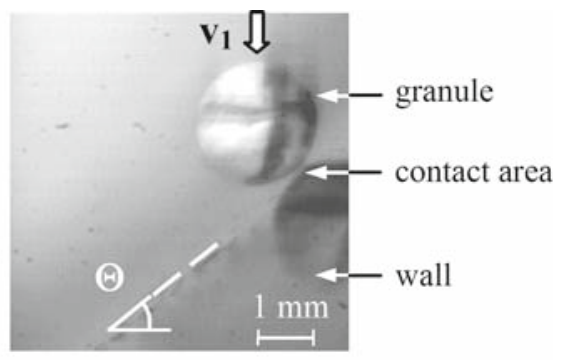

Time $t=0$

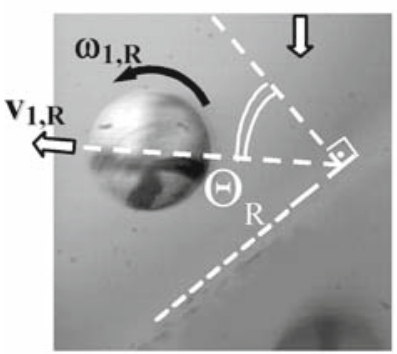

Time $t=2.2 \mathrm{~ms}$

Fig. 35 Images from the high-speed video recording of rebound of a zeolite 4 A granule $(d=2.3 \mathrm{~mm})$ after the impact on steel wall

impact angle close to $30^{\circ}$ (for $\gamma-\mathrm{Al}_{2} \mathrm{O}_{3}$ and zeolite $4 \mathrm{~A}$ ) and to $20^{\circ}$ (for sodium benzoate) Fig. 36b. The presence of minima in the function of tangential restitution coefficient is similar 
Fig. 36 Restitution coefficient in a normal and $\mathbf{b}$ tangential direction versus the impact angle for three examined granules at impact velocity of about $2.3 \mathrm{~m} / \mathrm{s}$
Fig. 37 Rebound angle (a) and angular velocity after impact (b) versus the impact angle for three examined granules at the impact velocity of about $2.3 \mathrm{~m} / \mathrm{s}$

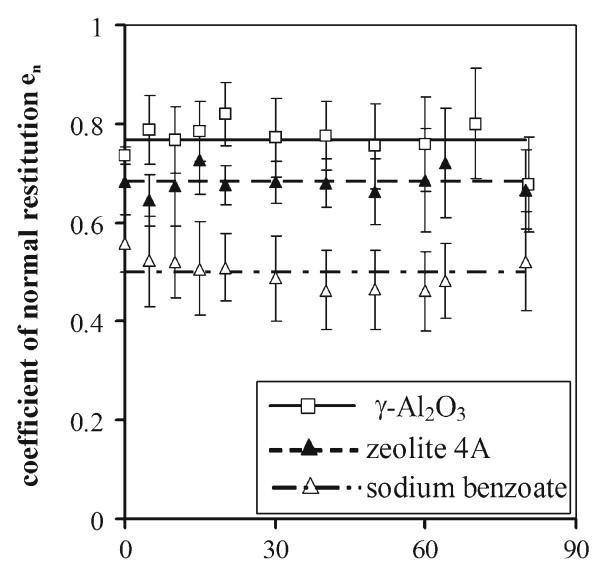

(a) impact angle $\Theta$ in ${ }^{\circ}$

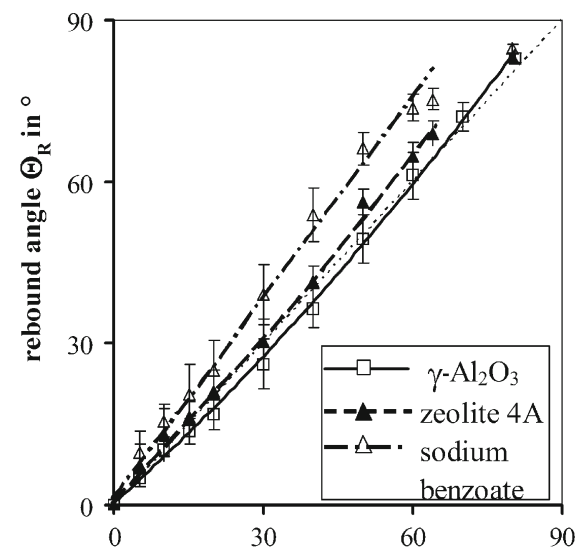

(a) impact angle $\Theta$ in ${ }^{\circ}$

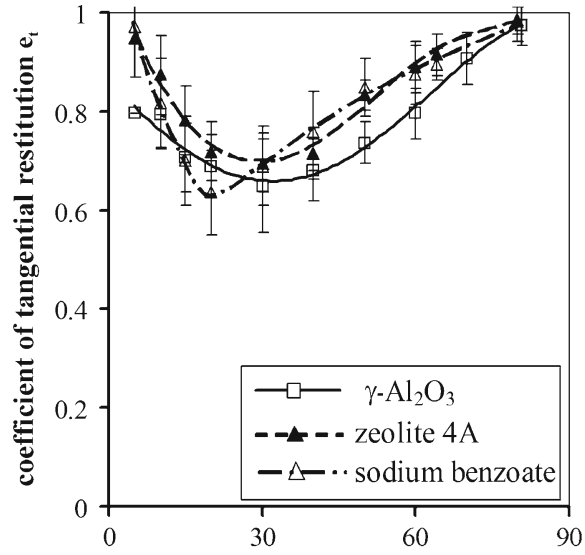

(b) impact angle $\Theta$ in ${ }^{\circ}$

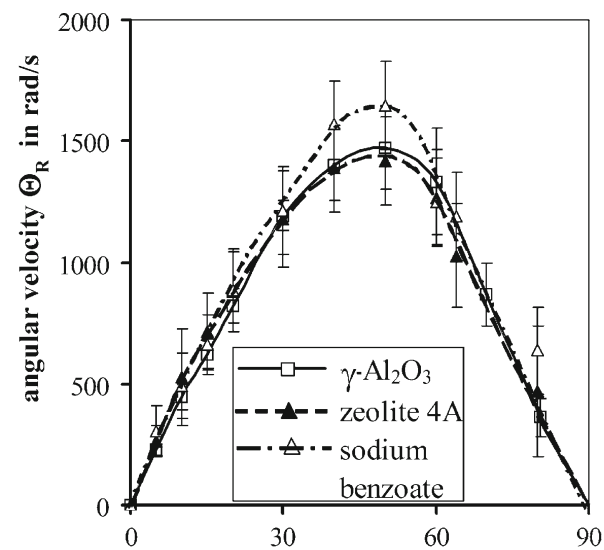

(b) impact angle $\Theta$ in ${ }^{\circ}$ to that observed by Dong and Moys [18], Kharaz et al. [46] for different solid particles and it could be explained by transition from rolling at small angles to sliding at large angles.

The increasing the inclination above the minimum increases the coefficient of tangential restitution which exceeds the normal coefficient of restitution and reaches a value of 1 at angles close to $90^{\circ}$ by glancing incidence. In the sliding regime (at impact angles higher $50^{\circ}$ ) the tangential coefficient of restitution has the largest value for sodium benzoate and the least value for $\gamma-\mathrm{Al}_{2} \mathrm{O}_{3}$ as compared to the examined granules. Hence, this sequence is inversely to the coefficient of normal restitution of these granules.

Figure 37 summarizes the measurements of rebound angles and angular velocities of granules examined at impact angles from $0^{\circ}$ to $80^{\circ}$. When the impact takes place at an angle between $10^{\circ}$ and $55^{\circ}$, the rebound angle of $\gamma-\mathrm{Al}_{2} \mathrm{O}_{3}$ granules is slightly lower than the impact angle. The dotted line shows an ideal case of rotation at $\Theta=\Theta_{R}$ and the coefficient of friction: $\mu \rightarrow 0$. The shape of particles showed an important influence on the rebound behaviour at oblique impact. The small deviation from spherical shape for zeolite and great for sodium benzoate particles increases their rebound angle, which is always higher than the impact angle, Fig. 37a. Moreover, the particle roughness influences the collision behaviour and therefore the rebound angle.

The angular velocity after rebound increases with increasing the impact angle, reaches a maximum at an angle of about $50^{\circ}$ that shows the transition from rolling to sliding, Fig. 37b.

\section{Conclusions}

To simulate the rapid and collisional flow of particle beds by DEM, the normal and tangential restitution coefficients are usually required. In this work the mechanical behaviour and the associated restitution coefficients of various spherical granules were determined through slow compression and rapid impact. In the case of compression, $\gamma-\mathrm{Al}_{2} \mathrm{O}_{3}$, zeolites $13 \mathrm{X}$ and $4 \mathrm{~A}$ granules show both elastic and elastic-plastic behaviour. The Hertz theory predicts satisfactorily the elastic force-displacement behaviour of these granules. Therefore, Eq. (6) may be used in DEM with obtained modulus of elasticity and elastic contact stiffness. To describe the elastic-plastic non-adhesive deformation beyond the yield point a force-displacement model (Eq. (25)) was developed. 
Characteristic parameters are the contact pressure and the deformation at the yield point. These were determined using measured force-displacement curves.

The contact stiffness of granules increases with increasing displacement in both the elastic and the elastic-plastic ranges. Due to plastic deformation beyond yield point, the increase of elastic-plastic stiffness with deformation is less than by elastic stiffness. Moreover, the increase in granule diameter leads to increase in stiffness.

The force-displacement curves of sodium benzoate granules are linear, i.e. the stiffness is constant during plastic deformation, which confirms the perfectly plastic model, Eq. (35). This model can be recommended for DEM as a simple force-displacement relationship for loading of ideally plastic spherical granules. A good agreement between calculated and measured radii of plastic deformed contact area was obtained. The measured compressive strength and yield pressure of plastic granules are independent of the granule size.

Important effects of repeated loading on the deformation behaviour of granules were described. The granules show hardening during cyclic stressing at constant load amplitude. However, the modulus of elasticity and the yield point of the granule remain constant in each cycle but the elastic stiffness increases due to increase of the initial contact area. With a comfortable model (Eq. (59)) based on plastic deformation in the first cycle and a saturation parameter, the decrease and accumulation of plastic deformation with increasing number of cycles could be predicted. Moreover, based on the Hertz law an expression to calculate the elastic stiffness during cycling loading was derived, Eq. (60). A good agreement between this model and the stiffness evolution in cyclic tests of zeolite $13 \mathrm{X}$ granules was obtained.

Moreover, the cyclic tests showed that hardening of granules only takes place locally in the contact range where the maximum pressure during the compression occurs. The largest compaction of the microstructure occurs in the first cycle due to plastic deformation.

After reaching certain saturation in the plastic deformation, the granule behaves elastic-plastically and the restitution coefficient remains constant. Therefore, in a fluidized bed the effect of hardening due to repeated impacts of granules on the magnitude of restitution coefficient will only be relevant during the first impacts of granules. As a first approximation of contact behaviour in DEM models, a constant value of the restitution coefficient can be assumed.

An additional effect on the cyclic hardening is the magnitude of maximum load. If this increase is before saturation than the plastic deformation starts again, this significantly reduces both the restitution coefficient and the contact stiffness.

The energy absorption during impact was found to be lower than during compression, although the sequence of granules from elastic-plastic to dominantly plastic behaviour is the same in both stressing modes. Therefore, to predict the energy absorption of granules during impact, the values of restitution coefficient obtained in free-fall experiments should be used in DEM. Moreover, the restitution coefficient of granules is independent of the impact velocity in the examined range of $0.5-4.5 \mathrm{~m} / \mathrm{s}$ and of the maximum compressive load. For DEM simulations of a fluidized bed with dry granules, where the particle velocity is generally not higher then $4.5 \mathrm{~m} / \mathrm{s}$, a constant coefficient of restitution can safely be assumed.

From the study of oblique impact is found that the coefficient of normal restitution is independent of the impact angle. Therefore, the tangential restitution coefficient shows minimum value at angles in the range of $20^{\circ}-30^{\circ}$. The rebound angle of $\gamma-\mathrm{Al}_{2} \mathrm{O}_{3}$ granules is slightly lower (in the range of impact angles of $10^{\circ}-55^{\circ}$ ) or equal to the impact angle. Because of the deviation from sphericity and high roughness the rebound angle of zeolite 4A and sodium benzoate granules is higher than the impact angle. The angular velocity after rebound shows a maximum at an angle of about $50^{\circ}$.

In future work, the obtained mechanical behaviour of granules will be used to select the appropriate contact model for their implementation in DEM and to analyze the dynamics of collisional particle flow in fluidized beds.

Acknowledgments The authors are grateful to the Institute of Experimental Physics, Otto-von-Guericke-University of Magdeburg for the rent of the high-speed camera used in this study. We also thank M.Sc. L. Burai and M.Sc. S. Horbach for their help during performing of the experiments.

Open Access This article is distributed under the terms of the Creative Commons Attribution Noncommercial License which permits any noncommercial use, distribution, and reproduction in any medium, provided the original author(s) and source are credited.

\section{References}

1. Achenbach, J.D.: Wave Propagation in Elastic Solids. Elsevier, New York (1987)

2. Adams, M.J., Briscoe, B.J., Sinha, S.K.: An indentation study of an elastoviscoplastic material. Philos. Mag. A 74, 1225-1233 (1996)

3. Adams, M.J., Lawrence, C.J., Ursob, M.E.D., Rance, J.: Modelling collisions of soft agglomerates at the continuum length scale. Powder Technol. 140, 268-279 (2004)

4. Agniel, Y.: Bedeutung der Einzelgranalieneigenschaften zur Defektvermeidung in trockengepressten keramischen Modellpulvern. Doctoral dissertation, University of Karlsruhe (1992)

5. Antonyuk, S.: Deformations- und Bruchverhalten von kugelförmigen Granulaten bei Druck- und Stoßbeanspruchung. Doctoral Dissertation, University of Magdeburg, Docupoint Publishers (2006)

6. Antonyuk, S., Khanal, M., Tomas, J., Heinrich, S., Mörl, L.: Impact breakage of spherical granules: experimental study and DEM simulation. Chem. Eng. Process. 45, 838-856 (2006) 
7. Backhaus, G.: Deformationsgesetze. Akademie-Verlag, Berlin (1983)

8. Balevičius, R., Kačianauskas, R., Mroz, Z., Sielamowicz, I.: Discrete element method applied to multiobjective optimization of discharge flow parameters in hoppers. In: Structural and Multidisciplinary Optimization, pp. 163-175. Springer, London (2006)

9. Baskaran, A., Dufty, J.W., Brey, J.J.: Transport coefficients for the hard-sphere granular fluid. Phys. Rev. E 77, 3 (2008)

10. Beekman, W.J., Meesters, G.M.H., Becker, T., Gaertner, A., Gebert, M., Scarlett, B.: Failure mechanism determination for industrial granules using a repeated compression test. Powder Technol. 130, 367-376 (2003)

11. Brilliantov, N.V., Spahn, F., Hertzsch, J.-M., Pöschel, T.: Model for collision in granular gases. Phys. Rev. E 53, 5 (1996)

12. Buchholtz, V., Pöschel, T., Tillemans, H.J.: Simulation of rotating drum experiments using noncircular particles. Phys. A 216, 199212 (1995)

13. Buchholtz, V.: Molekulardynamische Untersuchungen granularer Stoffe. Doctoral dissertation, Humboldt-University zu Berlin (1994)

14. Carey, W.F., Bosanquet, C.H.: A study of crushing brittle solids. J. Soc. Glass Technol. 17, 384-411 (1933)

15. Chandramohan, R., Powell, M.S.: Measurement of particle interaction properties for incorporation in the discrete element method simulation. Miner. Eng. 18, 1142-1151 (2005)

16. Coaplen, J., Stronge, W.J., Ravani, B.: Work equivalent composite coefficient of restitution. Int. J. Impact Eng. 30, 581-591 (2004)

17. Davies, R.M.: Determination of static and dynamic yield stresses using a steel ball. Proc. R. Soc. Lond. A 197(1050), 416-432 (1949)

18. Dong, H., Moys, M.H.: Experimental study of oblique impacts with initial spin. Powder Technol. 161, 22-31 (2006)

19. Fischer-Cripps, A.C.: Introduction to Contact Mechanics. Springer, Berlin (2000)

20. Foerster, S.F., Louge, M.Y., Chang, H., Allia, K.: Measurements of the collision properties of small spheres. Phys. Fluids 6(3), 1108-1115 (1994)

21. Fu, J.S., Cheong, Y.S., Reynolds, G.K., Adams, M.J., Salman, A.D., Hounslow, M.J.: Impact deformation and rebound of wet granules, an experimental study of the variability in the properties and quality of wet granules. Powder Technol. 140, 209216 (2004)

22. Goldhirsch, I.: Rapid granular flows. Annu. Rev. Fluid Mech. 35, 267-293 (2003)

23. Goldsmith, W.: Impact: The Theory and Physical Behavior of Colliding Solids. Edward Arnold Ltd, London (1960)

24. Grof, Z., Kohout, M., Štěpánek, F.: Multi-scale simulation of needle-shaped particle breakage under uniaxial compaction. Chem. Eng. Sci. 62, 1418-1429 (2007)

25. Gröger, T., Tüzün, U., Heyes, D.M.: Modelling and measuring of cohesion in wet granular materials. Powder Technol. 133, 203215 (2003)

26. Guoping, L., Thornton, C., Adams, M.J.: Discrete particle simulation of agglomerate impact coalescence. Chem. Eng. Sci. 53, 3381-3391 (1988)

27. Gyenis, J., Ulbert, Z.s., Szépvölgyi, J., Tsuji, Y.: Discrete particle simulation of flow regimes in bulk solids mixing and conveying. Powder Technol. 104, 248-257 (1999)

28. Hagedorn, P.: Technische Mechanik. Bd. 2. Festigkeitslehre. Harri Deutsch Publishers, Frankfurt am Main, Thun (1995)

29. Hassanpour, A., Antony, S.J., Ghadiri, M.: Effect of size ratio on the behaviour of agglomerates embedded in a bed of particles subjected to shearing: DEM analysis. Chem. Eng. Sci. 62, 935942 (2007)

30. Hertz, H.: Über die Berührung fester elastischer Körper. J. Die Reine Und Angewandte Mathematik 92, 156-171 (1882)
31. Hoomans, B.P.B., Kuipers, J.A.M., Briels, W.J., Swaaij, van W.P.M.: Discrete particle simulation of bubble and slug formation in a two-dimensional gas-fluidised bed: a hard-sphere approach. Chem. Eng. Sci. 51, 99-118 (1996)

32. Huang, H., Dallimore, M.P., Pan, J., McCormick, P.G.: An investigation of the effect of powder on the impact characteristics between a ball and a plate using free falling experiments. Mat. Sci. Eng. A 241, 38-47 (1998)

33. Hunter, S.C.: Energy adsorbed by elastic waves during impact. J. Mech. Phys. Solids 5, 162-171 (1956)

34. Iveson, S.M., Litster, J.D.: Liquid-bound granule impact deformation and coefficient of restitution. Powder Technol. 99, 234 242 (1998)

35. Iwashita, K., Oda, M.: Micro-deformation mechanism of shear banding process based on modified distinct element method. Powder Technol. 109, 192-205 (2000)

36. Iwashita, K., Tarumi, Y., Casaverde, L., Uemura, D., Meguro, K., Hakuno, M. : Granular assembly simulation for ground collapse. In: Satake, M., Jenkins, J.T. (eds.) Micromechanics of Granular Materials, pp. 125-132. Elsevier, Amsterdam (1988)

37. Jenkins, J.T., Richman, M.W.: Plane simple shear of smooth inelastic circular disks: the anisotropy of the second moment in the dilute and dense limits. J. Fluid Mech. 171, 53-69 (1986)

38. Johnson, K.L.: Contact Mechanics. Cambridge University Press, Cambridge (1985)

39. Johnson, K.L., Pollock, H.M.: The role of adhesion in the impact of elastic spheres. J. Adhes. Sci. Technol. 8(11), 13231332 (1994)

40. Kafui, K.D., Thornton, C., Adams, M.J.: Discrete particle-continuum fluid modelling of gas-solid fluidised beds. Chem. Eng. Sci. 57, 2395-2410 (2002)

41. Kaneko, Y., Shiojima, T., Horio, M.: DEM simulation of fluidized beds for gas-phase olefin polymerization. Chem. Eng. Sci. 54, 5809-5821 (1999)

42. Kantak, A.A., Davis, R.H.: Collisions of spheres with wet and dry porous layers on a solid wall. Chem. Eng. Sci. 61, 417-427 (2006)

43. Kaskas, A.A.: Schwarmgeschwindigkeit in Mehrkornsuspensionen am Beispiel der Sedimentation. Doctoral dissertation, Technical University of Berlin (1970)

44. Kawaguchi, T., Sakamoto, M., Tanaka, T., Tsuji, Y.: Quasithree-dimensional numerical simulation of spouted beds in cylinder. Powder Technol. 109, 3-12 (2000)

45. Khanal, M.: Simulation of crushing dynamics of an aggregate-matrix composite by compression and impact stressings. Doctoral dissertation, University of Magdeburg, Docupoint Publishers (2005)

46. Kharaz, A.H., Gorham, D.A., Salman, A.D.: An experimental study of the elastic rebound of spheres. Powder Technol. 120, 281291 (2001)

47. Kishino, Y. : Disc model analysis of granular media. In: Satake, M., Jenkins, J.T. (eds.) Micromechanics of Granular Materials, pp. 143-152. Elsevier, Amsterdam (1988)

48. Koller, M.G.: Elastischer Stoss von Kugeln auf dicke Platten. Doctoral disseratation, ETH Zürich (1983)

49. Konietzky, H.: Numerische simulation in der Geomechanik mittels expliziter Verfahren. Doctoral dissirtation, Technical University Bergakademie Freiberg, Freiberg (2001)

50. Kruggel-Emden, H., Simsek, E., Rickelt, S., Wirtz, S., Scherer, V.: Review and extension of normal force models for the discrete element method. Powder Technol. 171, 157-173 (2006)

51. Krupp, H., Sperling, G.: Haftung kleiner Teilchen an Feststoffen-Teil II: Theorie. Zeitschrift für Angewandte Mathematik Und Physik 19, 259-265 (1965)

52. Kuo, H.P., Knight, P.C., Parker, D.J., Tsuji, Y., Adams, M.J., Seville, J.P.K.: The influence of DEM simulation parameters on 
the particle behaviour in a V-mixer. Chem. Eng. Sci. 57, 36213638 (2002)

53. Kuwabara, G., Kono, K.: Restitution coefficient in a collision between two spheres. Jpn. J. Appl. Phys. 26, 1230-1233 (1987)

54. Kwapinska, M., Saage, G., Tsotsas, E.: Mixing of particles in rotary drums: a comparison of discrete element simulations with experimental results and penetration models for thermal processes. Powder Technol. 161, 69-78 (2006)

55. Labous, L., Rosato, A.D., Dave, R.N.: Measurements of collisional properties of spheres using high-speed video analysis. Phys. Rev. E 56(5, B), 5717-5725 (1997)

56. Landau, L.D., Lifschitz, E.M.: Theoretische Physik. Band VII: Elastizitätstheorie. Fizmatlit, Moskau (2001)

57. Li, J.: Euler-Lagrange simulation of flow structure formation and evolution in dense gas-solid flows. PhD thesis, University of Twente, Enschede (2003)

58. Link, J.M., Cuypers, L.A., Deen, N.G., Kuipers, J.A.M.: Flow regimes in a spout-fluid bed: a combined experimental and simulation study. Chem. Eng. Sci. 60, 3425-3442 (2005)

59. Lorenz, A., Tuozzolo, C., Louge, M.Y.: Measurements of impact properties of small, nearly spherical particles. Exp. Mech. 37, 292-298 (1997)

60. Louge, M.Y, Adams, M.E.: Anomalous behavior of normal kinematic restitution in the oblique impacts of a hard sphere on an elastoplastic plate. Physical Rev. E 65, 021303 (2002)

61. Luding, S.: Molecular dynamics simulations of granular materials. In: Hinrichsen, H., Wolf, D. (eds.) Physics of Granular Media, pp. 299-324. Wiley-VCH, Berlin (2004)

62. Lun, C.K.K., Savage, S.B., Jeffrey, D.J., Chepurniy, N.: Kinetic theories for granular flow: inelastic particles in Couette flow and slightly inelastic particles in a general flowfield. J. Fluid Mech. 140, 189-222 (1984)

63. Lungfiel, A.: Ermittlung von Belastungsgrößen mittels der Diskrete-Elemente-Methode für die Auslegung von Sturzmühlen. Doctoral dissertation, Technical University Bergakademie Freiberg, Freiberg (2002)

64. Mangwandi, C., Cheong, Y.S., Adams, M.J., Hounslow, M.J., Salman, A.D.: The coefficient of restitution of different representative types of granules. Chem. Eng. Sci. 62, 437-450 (2007)

65. Matuttis, H.G., Luding, S., Herrmann, H.J.: Discrete element simulations of dense packings and heaps made of spherical and nonspherical particles. Powder Technol. 109, 278-292 (2000)

66. Moreno-Atanasio, R., Xu, B.H., Ghadiri, M.: Computer simulation of the effect of contact stiffness and adhesion on the fluidization behaviour of powders. Chem. Eng. Sci. 62, 184-194 (2007)

67. Ning, Z., Ghadiri, M.: Distinct element analysis of attrition of granular solids under shear deformation. Chem. Eng. Sci. 61, 5991-6001 (2006)

68. Odagi, K., Tanaka, T., Yamane, K.: DEM simulation of compression test of particles. In: Proceedings of World Congress on Particle Technology, Vol 4, Sydney (2002)

69. Piechatzek, T., Kwade, A.: DEM-Approach for numerical investigation of grinding media motion in stirred media mills. In: Book of Abstracts, 13.4, PARTEC 2007, International Congress on Particle Technology, Nürnberg (2007)

70. Pisarenko, G.S., Agarev, V.A., Kvitka, A.L., Popkov, V.G., Umanskii, E.S.: Strength of Materials. Vischa schkola, Kiev (1986)

71. Pitchumani, R., Meesters, G.M.H., Scarlett, B.: Breakage behaviour of enzyme granules in a repeated impact test. Powder Technol. 130, 421-427 (2003)

72. Pöschel, T., Brilliantov, N.V.: Extremal collision sequences of particles on a line: Optimal transmission of kinetic energy. Phys. Rev. E 63, 021505 (2001)

73. Pöschel, T., Luding, S.: Granular Gases. Springer, New York (2000)
74. Pöschel, T., Schwager, T.: Computational Granular Dynamics, Models and Algorithms. Springer, New York (2005)

75. Pouyet, J., Lataillade, J.L.: Dynamic investigation of hard viscoelastic materials by ball bouncing experiments. J. Mat. Sci. 10, 2112-2116 (1975)

76. Riehle, M., Simmchen, E.: Grundlagen der Werkstofftechnik. Deutscher Verlag für Grundstoffindustrie, Stuttgart (2002)

77. Rumpf, H.: Die Einzelkornzerkleinerung als Grundlage einer technischen Zerkleinerungswissenschaft. Chemie Ingenieur Technik 37, 187-202 (1965)

78. Samimi, A., Hassanpour, A., Ghadiri, M.: Single and bulk compressions of soft granules: experimental study and DEM evaluation. Chem. Eng. Sci. 60, 3993-4004 (2005)

79. Schäfer, J., Dippel, S., Wolf, D.E.: Force schemes in simulations of granular materials. J. de Physique I 6(1), 5-20 (1996)

80. Schönert, K.: Einzelkorn-Druckzerkleinerung und Zerkleinerungskinetik, Untersuchungen an Kalkstein-, Quarz-, und Zementklinkerkörnern des Größenbereiches 0,1 bis $3 \mathrm{~mm}$. Doctoral dissertation, University of Karlsruhe (1966)

81. Schubert, H.: Handbuch der Mechanischen Verfahrenstechnik. Bd. 1. Wiley, Weinheim (2003)

82. Schubert, W., Khanal, M., Tomas, J.: Impact crushing of particle-particle compounds-experiment and simulation. Int. J. Min. Process. 75, 41-52 (2005)

83. Seifried, R., Schiehlen, W., Eberhard, P.: Numerical and experimental evaluation of the coefficient of restitution for repeated impacts. Int. J. Impact Eng. 32, 508-524 (2005)

84. Sheng, Y., Briscoe, B.J., Maung, R., Rovea, C.: Compression of polymer bound alumina agglomerates at the micro deformation scale. Powder Technol. 140, 228-239 (2004)

85. Sommerfeld, M., Huber, N.: Experimental analysis and modelling of particle-wall collisions. Int. J. Multip. Flow 25, 14571489 (1999)

86. Stevens, A.B., Hrenya, C.M.: Comparison of soft-sphere models to measurements of collision properties during normal impacts. Powder Technol. 154, 99-109 (2005)

87. Stoianovici, D., Harmuzlu, Y.: A critical study of the applicability of rigid-body collision theory. J. Appl. Mech. 63, 307-316 (1996)

88. Stronge, W.J.: Impact Mechanics. Cambridge University Press, Cambridge (2000)

89. Szabó, I.: Höhere technische Mechanik. Springer, Berlin (2001)

90. Takeuchi, S., Wang, S., Rhodes, M.: Discrete element simulation of a flat-bottomed spouted bed in the 3-D cylindrical coordinate system. Chem. Eng. Sci. 59, 3495-3504 (2004)

91. Targ, S.M.: Short Course of Theoretical Mechanics. Nauka, Moscow (1966)

92. Tavares, L.M., King, R.P.: Modeling of particle fracture by repeated impacts using continuum damage mechanics. Powder Technol. 123, 138-146 (2002)

93. Thornton, C.: Coefficient of restitution of collinear collisions of elastic-perfectly plastic spheres. J. Appl. Mech. 64, 383-386 (1997)

94. Thornton, C., Ning, Z.: A theoretical model for the stick/bounce behaviour of adhesive, elastic-plastic spheres. Powder Technol. 99, 154-162 (1998)

95. Thornton, C., Ciomocos, M.T., Adams, M.J.: Numerical simulations of diametrical compression tests on agglomerates. Powder Technol. 140, 258-267 (2004)

96. Tomas, J.: Particle adhesion fundamentals and bulk powder consolidation. KONA-Powder Particle 18, 157-169 (2000)

97. Tomas, J.: Assessment of mechanical properties of cohesive particulate solids-part 1: particle contact constitutive model. Part. Sci. Technol. 19(2), 95-110 (2001)

98. Tomas, J.: Adhesion of ultrafine particles-a micromechanical approach. Chem. Eng. Sci. 62, 1997-2010 (2007) 
99. Tomas, J.: Adhesion of ultrafine particles-energy absorption at contact. Chem. Eng. Sci. 62, 5925-5939 (2007)

100. Tomas, J.: Mechanics of Particle Adhesion. Manuscript, Magdeburg (2008)

101. Tsuji, Y., Tanaka, T., Ishida, T.: Lagrangian numerical simulation of plug flow of cohesionless particles in a horizontal pipe. Powder Technol. 71, 239-250 (1992)

102. Tsuji, Y., Kawaguchi, T., Tanaka, T.: Discrete particles simulation of 2-dimensional fluidized bed. Powder Technol. 77, 79-87 (1993)

103. Tykhoniuk, R., Tomas, J., Luding, S., Kappl, M., Heim, L., Butt, H-J.: Ultrafine cohesive powders: from interparticle contacts to continuum behaviour. Chem. Eng. Sci. 62, 2843-2865 (2007)

104. Buijtenen, M.S.van, Deen, N.G., Heinrich, S., Antonyuk, S., Kuipers, J.A.M.: A discrete element study of wet particle-particle interaction during granulation in a spout fluidized bed. Can. J. Chem. Eng. 9999, 1-10 (2009)

105. Venugopal, R., Rajamani, R.K.: 3D simulation of charge motion in tumbling mills by the discrete element method. Powder Technol. 115, 157-166 (2001)

106. Walton, O.R., Braun, R.L.: Viscosity, granular-temperature, and stress calculations for shearing assemblies of inelastic, frictional disks. J. Rheol. 30, 949-980 (1986)
107. Walton, O.R., Braun, R.L., Mallon, R.G., Gervelli, D.M. : Particle-dynamics calculations of gravity flow of inelastic, frictional spheres. In: Satake, M., Jenkins, J.T. (eds.) Micromechanics of Granular Materials, pp. 153-161. Elsevier Science Publishers B.V., Amsterdam (1988)

108. Weir, G., Tallon, S.: The coefficient of restitution for normal incident, low velocity particle impacts. Chem. Eng. Sci. 60, 36373647 (2005)

109. Wu, C., Li, L., Thornton, C.: Rebound behaviour of spheres for plastic impacts. Int. J. Impact Eng. 28, 929-946 (2003)

110. Ye, M., Hoef, M.A.van der, Kuipers, J.A.M.: A numerical study of fluidization behavior of Geldart A particles using a discrete particle model. Powder Technol. 139, 129-139 (2004)

111. Zhang, Z.P., Liu, L.F., Yuan, Y.D., Yu, A.B: A simulation study of the effects of dynamic variables on the packing of spheres. Powder Technol. 116, 23-32 (2001)

112. Zhou, H., Flamant, G., Gauthier, D.: DEM-LES of coal combustion in a bubbling fluidized bed. Part I: gas-particle turbulent flow structure. Chem. Eng. Sci. 59, 4193-4203 (2004)

113. Ziegler, F.: Technische Mechanik der festen und flüssigen Körper. Springer, Wien (1985)

114. Zippelius, A.: Granular gases. Physica A 369(1), 143-158 (2006) 